\title{
Patterns of Harmful Alcohol Consumption among Truck Drivers: Implications for Occupational Health and Work Safety from a Systematic Review and Meta-Analysis
}

\author{
Nicola Luigi Bragazzi ${ }^{1, *(1)}$, Guglielmo Dini ${ }^{1,2}$ (i) , Alessandra Toletone ${ }^{3}$, Alborz Rahmani ${ }^{1}$, \\ Alfredo Montecucco ${ }^{1}$, Emanuela Massa ${ }^{1}$, Alessia Manca ${ }^{1}$, Ottavia Guglielmi ${ }^{4}$, \\ Sergio Garbarino ${ }^{4}$, Nicoletta Debarbieri ${ }^{1,2}$ and Paolo Durando ${ }^{1,2, *}$ (i) \\ 1 Department of Health Sciences (DISSAL), Postgraduate School of Occupational Medicine, University of \\ Genoa, Genoa 16132, Italy; guglielmo.dini@unige.it (G.D.); alborz.rahmani@edu.unige.it (A.R.); \\ alfredo.montecucco@edu.unige.it (A.M.); emanuela.massa@edu.unige.it (E.M.); \\ alessia.manca@edu.unige.it (A.M.); nicoletta.debarbieri@hsanmartino.it (N.D.) \\ 2 Occupational Medicine Unit, Policlinico San Martino Hospital, 16132 Genoa, Italy \\ 3 Occupational Medical Service, Local Health Unit 1, Liguria Regional Healthcare System, 18038 Imperia, \\ Italy; a.toletone@asl1.liguria.it \\ 4 Department of Neuroscience, Rehabilitation, Ophthalmology, Genetics, Maternal and Child \\ Health (DINOGMI), University of Genoa, 16132 Genoa, Italy; ottavia.guglielmi@gmail.com (O.G.); \\ sgarbarino.neuro@gmail.com (S.G.) \\ * Correspondence: dottornicolaluigibragazzi@gmail.com (N.L.B.); durando@unige.it (P.D.); \\ Tel.: +39-010-353-8133 (P.D.)
}

Received: 2 May 2018; Accepted: 28 May 2018; Published: 30 May 2018

\begin{abstract}
Alcohol consumption is one of the main causes of productivity losses arising from absenteeism, presenteeism, and workplace injuries. Among occupational categories most affected by the use of this substance, truck drivers are subject to risk factors and risky behaviors that can have a serious impact on their health, their work, and the general road safety. The use of alcohol during truck-driving activities is, indeed, an important risk factor for traffic accidents. The present systematic review and meta-analysis aims at synthesizing the literature regarding harmful alcohol consumption patterns among truck drivers in a rigorous way. A 'binge drinking' prevalence of $19.0 \%, 95 \%$ confidence interval or CI $(13.1,26.9)$ was present. An 'everyday drinking' pattern rate of $9.4 \%, 95 \%$ CI $(7.0,12.4)$ was found, while the rate of alcohol misuse according to the "Alcohol Use Disorders Identification Test" (AUDIT)— "Cut down-Annoyed-Guilty-Eye opener questionnaire" (CAGE) instruments was computed to be of $22.7 \%, 95 \%$ CI $(14.8,33.0)$. No evidence of publication bias could be found. However, there is the need to improve the quality of published research, utilizing standardized reliable instruments. The knowledge of these epidemiological data can be useful for decision makers in order to develop, design, and implement ad hoc adequate policies.
\end{abstract}

Keywords: harmful use of alcohol; truck-drivers; occupational health and well-being; systematic review and meta-analysis

\section{Introduction}

"If you bought it, a truck brought it." A popular saying.

Alcohol consumption is among the main causes of absenteeism, presenteeism, and workplace injuries [1-3]. In the USA, alcohol-induced impairment directly affects an estimated $15 \%$ of the workforce and causes more than $22 \%$ of the deaths as a result of injuries at work $[4,5]$. 
Concerning the relationship between using alcohol and accidents/injuries, studies have shown that drinking alcohol before driving was responsible for approximately $21-30 \%$ of car crash injuries in the general driving population [6-8]. Alcohol, indeed, impairs brake reaction time, steering responsiveness, and lane control. It also increases the tendency of speeding on the road and other high risk driving behaviors. It is noteworthy to remember that $5.9 \%$ of all global deaths result from the harmful use of alcohol, as well as 5.1\% of the world's diseases and injuries [9]. Over 1.2 million people die, and up to 50 million nonfatal injuries incur each year because of road accidents [10]. Fifteen percent of all deaths and $13 \%$ of all injuries and disabilities caused by traffic crashes are attributable to alcohol [11,12].

Truck drivers are an important part of worldwide trade and economy. In the field of transportation, trucks are used in freight movement over land, transporting raw materials, livestock, and finished goods from manufacturing plants to retail distribution centers. In the construction industry, they can be used as dump trucks and portable concrete mixers. It is estimated that there are approximately 1.7 million long-haul truck drivers in the USA [13], 260,000 in Australia [14], and more than 1.5 million in European countries [15].

Truck drivers have been reported as a highly vulnerable working population due to different risk factors [16-18] including hypertension, fatigue [19], obstructive sleep apnea (OSA) and sleep deprivation [20,21], and insufficient physical activity [22]. Other risk factors are exposure to diesel exhaust and risk of developing lung cancer [23], poor diet, obesity, dyslipidemia, and other metabolic disorders [24]. Furthermore, they are prone to risky behaviors and lifestyles such as smoking, drinking, using psychoactive substances, and having casual sexual contacts [25]. These risk factors and risky behaviors can have a relevant impact on their health and work ability [16-18], as well as work safety, increasing the risk of injuries and traffic accidents [26-28]. They can, indeed, lead to impairment in the physical and mental health, and together with anxiety and stressful conditions due to irregular working schedules, night shifts, the need for prolonged mental alertness, and high productivity demands [16,29-31], increase the rate of motor vehicle accidents (MVAs) [32-34]. Studies conducted over the past 20 years have shown a significant association between alcohol misuse and traffic accidents, even if the precise role it may play in the disproportionate involvement of large motor vehicles (e.g., trucks and busses) in MVAs remains equivocal [30]. Although countries have legislations that regulate the driving time in the transport sector, truck drivers still have to work for long uninterrupted shifts [35]. This could encourage the high use of stimulants, drugs, and alcohol [36].

Evidence from other occupations and work settings suggests that identifying and then intervening to alter workplace conditions associated with alcohol misuse may be an important means of prevention [37-42]. Major international organizations such as the World Health Organization (WHO) [43], the Council of the European Union [44], and the International Labor Office (ILO) [45] in several documents have maintained the need to actualize policies and programs focused on the issue of alcohol and work, pointing to the prevention of alcohol-related damage as a priority and encouraging actions to combat the alcohol use at the workplace by adopting specific measures. The alcohol consumption in truck drivers, besides being detrimental for the health, represents an important public and occupational safety concern, in that this work category is at high risk of occupational accidents and can jeopardize the safety of others. Nevertheless, in our country the extent of the problems related to the use of alcohol in the occupational category of truck-drivers is still unknown in depth, due to the paucity of available data, that can adequately inform measures to intervene at the workplace, together with shortcomings in legislation which impact on the collaboration between the stakeholders involved [46].

Therefore, the aim of this study was to fill this gap of knowledge, evaluating the prevalence rate of alcohol use and the harmful patterns of consumption among truck drivers; carrying out a systematic review and meta-analysis in such a way as to provide a scientific overview of this issue in order to equip the decision makers and the stakeholders with an updated synthesis of relevant studies. 
Our study adds to the recently published work by Girotto et al. [16] in that it significantly updates and expands the published systematic review and performs a rigorous quantitative synthesis of the available scientific evidences and systematically studies the determinants of alcohol use among truck drivers.

\section{Materials and Methods}

\subsection{Registration of Protocol with International Prospective Register of Systematic Reviews}

The protocol of the present study has been reported according to the "Preferred Reporting Items for Systematic Reviews and Meta-Analysis-Protocols" (PRISMA-P) guidelines [47]. In accordance with these guidelines, the systematic review protocol has been registered with the International Prospective Register of Systematic Reviews (PROSPERO) [48] on 1 April 2016 (registration number CRD42016037077) [49].

The results of the study are reported in line with the PRISMA guidelines [50].

\subsection{Data Sources and Search Strategy}

A systematic literature search has been performed searching different scholarly databases, including nine different bibliographic thesauri (namely, PubMed/MEDLINE (NLM), Scopus, SciVerse ScienceDirect, Science Citation Index Expanded (SCIE) and Social Sciences Citation Index from ISI/Web of Science, ProQuest Research Library, ABI/INFORM, CBCA), via the UNO per TUTTI Primo Central (Ex Libris) platform databases.

All prevalence studies on alcohol use among truck drivers were included in the current study. The search was performed using the following search terms: "(truckers OR truck drivers OR lorry OR commercial vehicles OR large good vehicles OR large vehicles OR heavy vehicles OR long vehicles OR trucking industry OR haul transport) AND (alcohol OR ethanol)". The search strategy was adapted for the other databases. Additionally, we searched reference lists of the chosen studies and prior reviews. We extensively mined different databases and we used a broad keyword string in order to capture the highest number of potentially relevant studies, minimizing the chances of missing pertinent items.

When it was not possible to make a decision on a study's inclusion or exclusion based on the title and/or abstract, the full text of the study was examined (Table 1).

Table 1. Search strategies criteria of the current meta-analysis.

\begin{tabular}{|c|c|}
\hline Search Strategy Item & Search Strategy \\
\hline Databases & $\begin{array}{l}\text { PubMed/MEDLINE (NLM), Scopus, SciVerse ScienceDirect, Science Citation Index Expanded } \\
\text { and Social Sciences Citation Index from ISI/Web of Science, ProQuest Research Library, } \\
\text { ABI/INFORM, CBCA, via the UNO per TUTTI Primo Central (Ex Libris) platform }\end{array}$ \\
\hline Language filter & None \\
\hline Time filter & None \\
\hline Keywords & $\begin{array}{c}\text { (truckers OR truck drivers OR lorry OR commercial vehicles OR large good vehicles OR large } \\
\text { vehicles OR heavy vehicles OR long vehicles OR trucking industry OR haul transport) AND } \\
\text { (alcohol OR ethanol) }\end{array}$ \\
\hline Exclusion criteria & $\begin{array}{c}\text { Editorial, letter to the editor, commentary, review; original article focusing on selected } \\
\text { subgroups of truck drivers }\end{array}$ \\
\hline Target journals & $\begin{array}{l}\text { Accident Analysis and Prevention; American Journal of Industrial Medicine; Applied Ergonomics; } \\
\text { Ergonomics; Health and Place; Human Factors; International Archives of Occupational and } \\
\text { Environmental Health; International Journal of Environmental Research and Public Health; International } \\
\text { Journal of Heavy Vehicle Systems; International Journal of Industrial Ergonomics; Journal of } \\
\text { Occupational and Environmental Medicine; Journal of Occupational Health; La Medicina del } \\
\text { Lavoro/Medicine, Health and Working Life; Occupational and Environmental Medicine; Proceedings of } \\
\text { the Human Factors and Ergonomics Society; Safety and Health at Work; Safety Science; Scandinavian } \\
\text { Journal of Work, Environment and Health; Traffic Injury Prevention; Transportation Research Part F } \\
\text { Traffic Psychology and Behavior; Transportation Research Record; Workplace Health and Safety }\end{array}$ \\
\hline
\end{tabular}




\subsection{Study Screening and Selection}

Once retrieved via the UNO per TUTTI Primo Central (Ex Libris) platform databases, duplicate studies were automatically removed. The list of non-redundant items was handled with the open source Review Manager 5 (RevMan 5) software.

The studies have been independently screened by two authors (NLB, GD) looking at study titles and/or abstracts for potential eligibility. Screening questions were developed and pilot-tested with a subset of records before implementation (Table 2). Disagreement was assessed using Cohen's $\kappa$ statistics and has been resolved through discussion; a third reviewer (AM) has been involved if necessary.

Table 2. Data extracted from the included studies in the current meta-analysis.

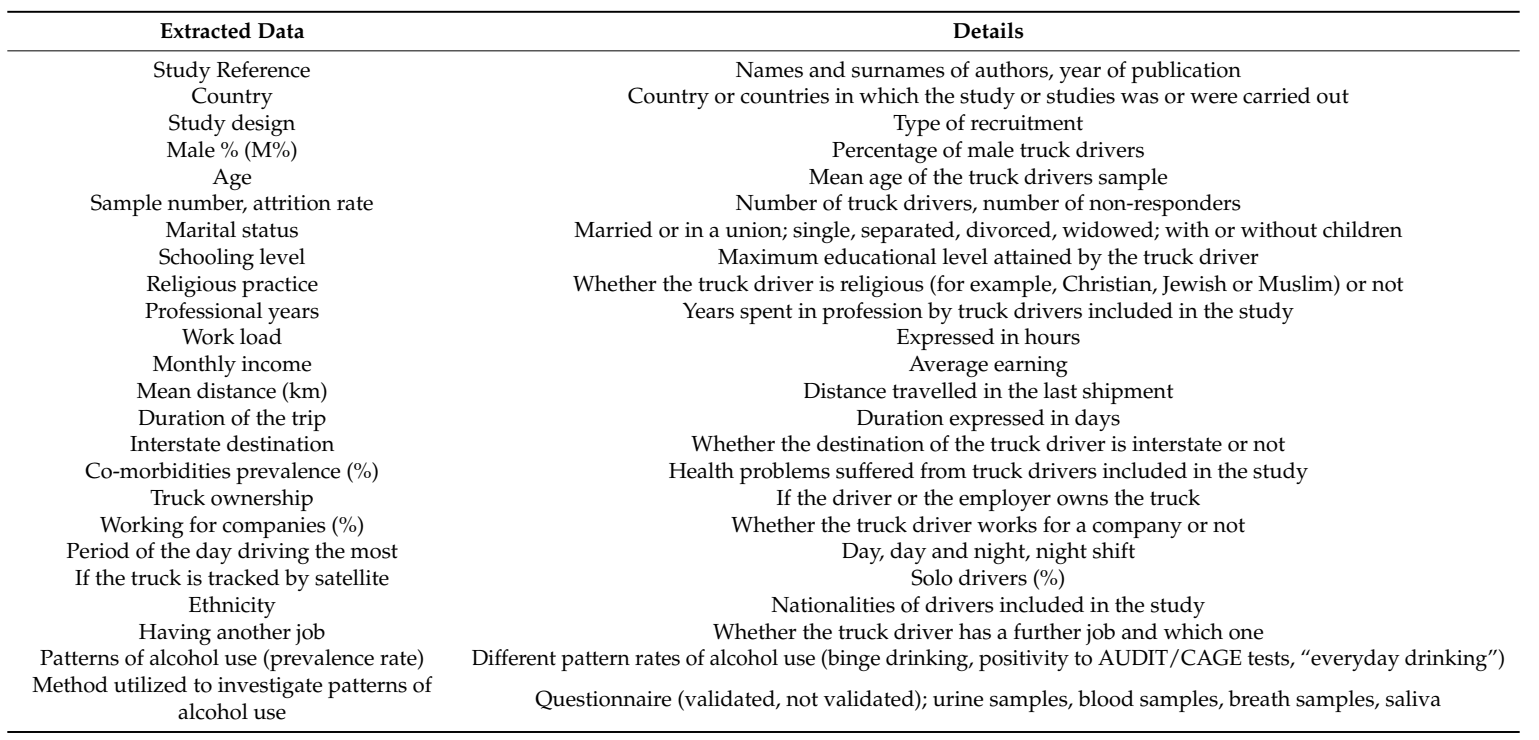

Abbreviations: AUDIT (Alcohol Use Disorders Identification Test); CAGE (Cut down-Annoyed-Guilty-Eye opener questionnaire).

We have provided tables with characteristics of included studies and of excluded studies with reasons for their exclusion (Tables 3-5).

Studies meeting the following PICOS/PECOS criteria were considered for inclusion:

- $\quad \mathrm{P}$ (population): truck-drivers.

- E (exposure): harmful use of alcohol.

- C (comparators): no comparators were considered in the present systematic review and meta-analysis.

- $\quad$ O (outcome/outcomes): prevalence of use of alcohol among truck drivers.

- $\quad$ S (study design): original studies designed as prevalence studies.

- Language: all languages available.

- Time: no time restraint.

\subsubsection{Alcohol Consumption Pattern}

In this systematic review and meta-analysis, we followed the WHO terminology related to alcohol consumption: "health-wise" (non-hazardous), "hazardous", and "harmful" alcohol use. The following paragraphs provide the readers with an overview of these definitions. We focused on alcohol pattern (frequency of drinking and number of drinks per occasion/event) rather than the mean alcohol intake, as the latter is an incomplete risk predictor of alcohol-related harm. 


\subsection{2. "Harmful Alcohol Use"}

The tenth edition of International Classification of Diseases (ICD-10) developed by the WHO defines "harmful alcohol use" as a pattern of substance use that causes damage to physical or mental health. This definition was closely similar to the concept of "alcohol abuse" developed by the American Psychiatric Association (APA) in the Diagnostic and Statistical Manual of Mental Disorders-Fourth edition (DSM-IV). Both of these concepts were introduced in order to gather clinically important problems associated with alcohol consumption that nonetheless could not be characterized as "alcohol dependence".

\subsection{3. "Binge Drinking"}

One pattern of harmful use is called "binge drinking", defined by the National Institute on Alcohol Abuse and Alcoholism (NIAAA) as a pattern of drinking four or more drinks for women, five or more drinks for men, in a two hour timeframe, which typically brings blood alcohol concentration (BAC) levels to $0.8 \mathrm{~g} / \mathrm{L}$.

This pattern is similar to another definition called "heavy episodic drinking" (HED), defined as drinking at least 60 grams or more of pure alcohol on at least one occasion in the past 30 days. Although the two terms are often used synonymously, we decided to use the former because it is more widely used by researchers.

\subsection{4. "Everyday Drinking"}

"Everyday drinking" among professional drivers can be considered as a pattern of consumption that increases the risk of accidents, which can therefore be harmful. Although this pattern has been referred to with several denominations, such as "daily drinking", "continuous drinking", and "steady drinking", we preferred "everyday drinking" because it has been correlated to problematic use and because it is the most unambiguous term.

\subsection{5. "AUDIT/CAGE"}

The Diagnostic and Statistical Manual of Mental Disorders - Fifth edition (DSM-V) introduced another concept, the "Alcohol Use Disorder" (AUD), which both overcomes the distinction between "abuse/harmful use" and "dependence" and includes them in a single category. The WHO has developed a tool to identify this pattern of use called Alcohol Use Disorder Identification Tool (AUDIT). A shorter three item version, called AUDIT-C identifies harmful patterns of consumption, such as frequency of drinking and "binge drinking" episodes, while the full 10-item AUDIT investigates symptoms of alcohol dependence as well. The CAGE (Cut down-Annoyed-Guilty-Eye) questionnaire is another tool previously developed to identify at risk alcohol users, an acronym for typical symptoms such as feeling the need to cut-down the amount of alcohol, being annoyed by criticism, feeling guilt, and using ethanol as an eye-opener in the morning.

\subsection{6. "Truck Drivers"}

In this report, "truck-drivers" are defined as any person whose activities involve driving lorry or commercial vehicles with the following characteristics: large, heavy or long vehicles.

\subsection{Appraisal of Study Quality}

Two reviewers are content experts (AM, GD) and one reviewer (NLB) is an experienced biostatistician/epidemiologist. The contents experts have only assessed potential publications with respect to the appropriateness of the research questions tested. The biostatistician has only evaluated the appropriateness of methods employed. Disagreement has been resolved by consensus.

The "Joanna Briggs Institute Critical Appraisal tools for use in JBI Systematic Reviews-Checklist for Prevalence Studies" has been used to assess the quality of studies included in the current 
systematic review and meta-analysis. This tool explores different domains of quality: namely, (i) the appropriateness of the sample frame to address the target population; (ii) the participants sampling technique; (iii) the adequateness of the sample size; (iv) the completeness of the description and details concerning the study subjects and the setting; (v) the coverage of the sample; (vi) the validity of the methods and (vii) their reliability; (viii) the appropriateness of the statistical analyses; and (ix) the adequateness of the response rate.

Concerning the third domain, the adequateness of the sample size was computed using the formula:

$$
n=\frac{Z^{2} \cdot P(1-P)}{d^{2}}
$$

where $n$ is the sample size, $Z$ is the $Z$ statistic for a given level of confidence (1.96), $P$ is the expected prevalence or proportion (in proportion of one; if, for instance, $20 \%, P$ is 0.2 ), and $d$ is the precision (in proportion of one; if $5 \%, d=0.05$ ).

Expecting a prevalence of alcohol consumption rate in the range $9-19 \%$, an adequate sample size should comprise a minimum of 131-236 subjects.

\subsection{Statistical Analysis}

For the meta-analysis, data have been extracted from the studies using a standardized documentation form (Table 2). Prevalence ratios were calculated as effect size (ES) estimates. The 95\% confidence intervals (CIs) were also generated. More in detail, the logit transformation $(l)$ approach was utilized in the current meta-analysis, being one of the possible approaches for pooling together raw prevalence data. The following equation was used to compute $l$ :

$$
l=\ln \left(\frac{p}{1-p}\right)
$$

where $p$ is the prevalence proportion.

Variance was computed using the equation:

$$
\operatorname{Var}(l)=\frac{1}{N \cdot p}+\frac{1}{N \cdot(1-p)}
$$

where $N$ is the population size.

The pooled $l$ was subsequently back-transformed to a proportion using the equation:

$$
p=\frac{e^{l}}{e^{l}+1}
$$

Additional analyses were performed after stratification considering all the variables listed in Table 2. Meta-analyses were carried out using the commercial software MedCalc Statistical Software version 16.8.4 (MedCalc Software bvba, Ostend, Belgium; https://www.medcalc.org; 2016) and Comprehensive Meta-Analysis CMA v3.

\subsection{Heterogeneity and Sensitivity Analysis}

Statistical heterogeneity has been assessed using the $I^{2}$ statistic. $I^{2}$ more than $50 \%$ was regarded as substantial heterogeneity [51,52]. To identify sources of variation, further stratification was performed relative to study quality and to performance of confirmatory tests. In addition, for the sensitivity analyses, the stability of the pooled estimate with respect to each study was investigated by excluding individual studies from the analysis. 


\subsection{Publication Bias}

Potential publication bias has been extensively investigated in the current systematic review and meta-analysis. First, we have visually inspected the funnel plot, looking at asymmetry of the graph. The funnel plot chosen in the current meta-analysis is the funnel plot of precision by logit event rate.

If asymmetry was present based on visual assessment, we performed exploratory analyses to investigate and adjust this using the Duval and Tweedie's trim-and-fill analysis [53]. In addition, the probability of publication bias has been tested using the Egger's linear regression test [54]. In conclusion, it should be emphasized that, in presence of statistically significant heterogeneity and with less than ten studies included, the findings of these tests should be interpreted with caution.

\section{Results}

Seventeen studies have been included in the present systematic review and meta-analysis $[8,12,26$, 27,55-67]. More in detail, from an initial list of 108,948 articles, after removing duplicates, 65,664 items remained. A pool of 65,632 articles were excluded, being deemed not relevant/pertinent with the research question. The full-text of 36 articles was assessed for eligibility, leading to 19 items excluded with reason $[28,38,39,68-83]$. Twelve questionnaire-based studies were excluded because they did not utilize validated, reliable instruments (such as CAGE or AUDIT), thus making the pooling of figures and their comparison methodologically unfeasible.

Of these studies, seven articles reported an unspecified alcohol consumption pattern, whereas two studies reported a generic consumption in the last year, meaning that the truck driver had consumed any alcoholic drink during the last year. While this could be useful to identify drinkers and non-drinkers, it is not-in the authors' opinion-useful for evaluating harmful consumption patterns, which is the main objective of the present study. Finally, one study reported alcohol consumption in terms of one per day, another study in terms of grams per kilogram, whilst one study counted the number of drinks per week.

Seven studies conducted biological monitoring of alcohol consumption (two using breath analysis, two utilizing urine samples, two saliva samples, and one blood).

Seventeen studies were retained in the qualitative synthesis of the literature and included in the quantitative synthesis (meta-analysis), as pictorially shown in Figure 1.

Table 3 reports studies excluded with reason, whereas the main characteristics of studies included in the meta-analysis are described in Table 4 . In Table 5, the critical appraisal of the methodological quality of the retained studies is reported. 


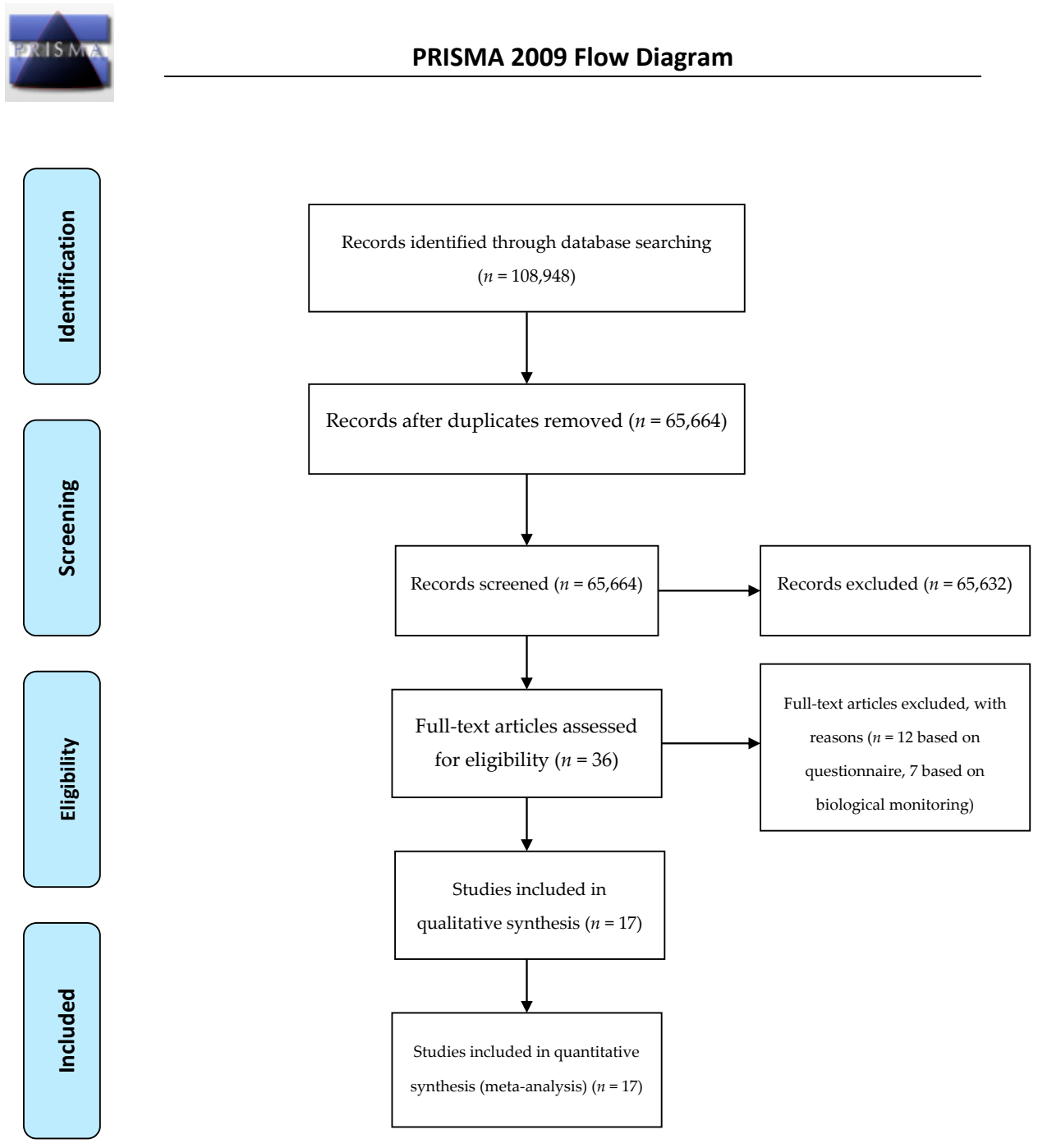

Figure 1. Flow-chart of the current systematic review and meta-analysis of alcohol consumption rate among truck drivers. 
Table 3. Characteristics of the studies excluded with reason from the meta-analysis for methodological heterogeneity related to the definition of alcohol consumption pattern.

\begin{tabular}{|c|c|c|c|}
\hline Study & Sample Size & Consumption Rate (\%) & Alcohol Consumption Definition \\
\hline \multicolumn{4}{|c|}{ Questionnaire-based } \\
\hline De Oliveira et al., 2015 [68] & 514 & 0.77 & $\begin{array}{c}\text { Generic consumption rate during the last } \\
\text { year }\end{array}$ \\
\hline Gay Anderson et al., 2008 [28] & 987 & 0.63 & $\begin{array}{c}\text { Generic consumption rate during the last } \\
\text { year }\end{array}$ \\
\hline Lemire et al., 2002 [69] & 2167 & $\begin{array}{c}0.61 \leq 2 \text { drinks / week, } \\
0.263-6 \text { drinks /week, } \\
0.02>15 \text { drinks / week; } \\
0.01 \text { admitted to drink on } \\
\text { the assessment day }\end{array}$ & Number of drinks/week \\
\hline Mansur Ade et al., 2015 [70] & 2228 & $0.23-0.37$ & Non-specified alcohol consumption \\
\hline Maarefvand et al., 2016 [71] & 349 & 0.014 & Non-specified alcohol consumption \\
\hline Masson and Monteiro, $2010[72,73]$ & 105 & 0.495 & Non-specified alcohol consumption \\
\hline Riva et al., 2010 [74] & 226 & $\begin{array}{c}0.51 \text { non-usual drinkers, } \\
0.47<0.5 \mathrm{~L} \text { alcohol/day } \\
0.03>0.5 \mathrm{~L} \text { alcohol } / \text { day } \\
0.25<0.5 \mathrm{~g} \text { alcohol } / \mathrm{kg}\end{array}$ & Consumption in terms of L alcohol/day \\
\hline Sakurai et al., 2007 [75] & 1465 & $\begin{array}{l}0.220 .5-1 \mathrm{~g} \text { alcohol } / \mathrm{kg} \\
0.07>1 \mathrm{~g} \text { alcohol } / \mathrm{kg}\end{array}$ & Consumption in terms of $\mathrm{g}$ alcohol $/ \mathrm{kg}$ \\
\hline Sangaleti et al., 2014 [76] & 250 & 0.668 & Non-specified alcohol consumption \\
\hline Takitane et al., 2013 [77] & 130 & 0.692 & Non-specified alcohol consumption \\
\hline Yonamine et al., 2013 [78] & 1277 & 0.259 & Non-specified alcohol consumption \\
\hline \multicolumn{4}{|c|}{ Biological monitoring_-saliva } \\
\hline Gjerde et al., 2012 [79] & 882 & 0.01 & $\begin{array}{l}\text { Automated enzymatic method using } \\
\text { alcohol dehydrogenase (cut-off } 0.2 \mathrm{~g} / \mathrm{L} \text { ) }\end{array}$ \\
\hline Yonamine et al., 2013 [78] & 1250 & 0.01 & $\begin{array}{l}\text { Headspace-gas chromatography-flame } \\
\text { ionization detection method (cut-off } 0.2 \\
\mathrm{~g} / \mathrm{L} \text { ) }\end{array}$ \\
\hline \multicolumn{4}{|c|}{ Biological monitoring-urine } \\
\hline Couper et al., 2002 [80] & 822 & 0.013 & $\begin{array}{l}\text { Headspace-gas chromatography-flame } \\
\text { ionization detection method (GCFID) }\end{array}$ \\
\hline Labat 2008 [81] & 1000 & 0.05 & $\begin{array}{c}\text { Enzymatic technique was used for ethanol } \\
\text { determination. Detection limit was } \\
\text { estimated at } 0.1 \mathrm{~g} / \mathrm{L}\end{array}$ \\
\hline \multicolumn{4}{|c|}{ Biological monitoring_-breath } \\
\hline Drummer et al., $2007[38,39]$ & 3974 & 0.01 & Breath test $0.5 \mathrm{~g} / \mathrm{L}$ \\
\hline Woratanarat et al., 2009 [82] & 200 & 0.05 & Breath test (Lion Alco meter SD-400) \\
\hline \multicolumn{4}{|c|}{ Biological monitoring_blood } \\
\hline Lund et al., 1988 [83] & 299 & 0.003 & $\begin{array}{l}\text { Gas chromatography with a nominal } \\
\text { detection threshold of } 0.01 \mathrm{~g} / \mathrm{dL} \text { in blood or } \\
\text { urine, three blood positives with values of } \\
0.01,0.02 \text { and } 0.03 \mathrm{~g} / \mathrm{dL}\end{array}$ \\
\hline
\end{tabular}


Table 4. Characteristics of the studies included in the current meta-analysis.

\begin{tabular}{|c|c|c|c|c|c|c|c|c|c|c|c|c|c|c|}
\hline $\begin{array}{l}\text { Study } \\
\end{array}$ & Sample Size & Binge Drinking & AUDIT/CAGE & Daily Drinking & Country & Age & Male & Marriage & Mean Distance & Experience Years & Work Load & For Companies & Schooling Level & Night Shift \\
\hline De Oliveira et al., 2016 [12] & 391 & 0.175 & NR & NR & Brazil & 37.7 & NR & 75.72 & 1149 & 12.41 & 11.99 & 57.03 & NR & 20.72 \\
\hline Domingos et al., 2010 [55] & 827 & NR & 0.418 & $N R$ & Brazil & 41.3 & 99.3 & 85.5 & NR & NR & $N R$ & $N R$ & 67 & NR \\
\hline Girotto et al., 2015 [27] & 670 & 0.291 & NR & NR & Brazil & 41.9 & 100 & NR & 934.1 & 18.1 & NR & NR & 58.2 & NR \\
\hline Jora et al., 2010 [56] & 496 & 0.258 & NR & NR & Brazil & 41.8 & 95.2 & 79 & NR & NR & NR & NR & NR & NR \\
\hline Knauth et al., 2011 [57] & 854 & NR & NR & 0.097 & Brazil & $\mathrm{NR}$ & 100 & 83.8 & NR & NR & NR & NR & 30.8 & NR \\
\hline $\begin{array}{l}\text { Korelitz et al., } 1993[26] \\
\text { Laragui et al. } 2011[58]\end{array}$ & 2945 & NR & 0.228 & NR & USA & $\mathrm{NR}$ & 89 & 69.6 & NR & $\mathrm{NR}$ & NR & $\mathrm{NR}$ & 81 & $\mathrm{NR}$ \\
\hline $\begin{array}{l}\text { Laraquie te al., } 20111 \text { [58] } \\
\text { Leopoldo et al., } 2015 \text { [59] }\end{array}$ & $\begin{array}{l}2134 \\
535\end{array}$ & $\begin{array}{c}\mathrm{NR} \\
0.174\end{array}$ & $\begin{array}{l}\mathrm{NR} \\
\mathrm{NR}\end{array}$ & $\begin{array}{l}0.118 \\
\mathrm{NR}\end{array}$ & $\begin{array}{c}\text { Morocco } \\
\text { Brazil }\end{array}$ & $\begin{array}{l}\text { NR } \\
37.8\end{array}$ & $\begin{array}{l}100 \\
100\end{array}$ & $\begin{array}{l}\mathrm{NR} \\
74.7\end{array}$ & $\begin{array}{c}\text { NR } \\
1127.3\end{array}$ & $\begin{array}{l}12.2 \\
12.5\end{array}$ & $\begin{array}{l}11.1 \\
12.1\end{array}$ & $\begin{array}{l}\text { NR } \\
609\end{array}$ & $\begin{array}{l}\mathrm{NR} \\
488\end{array}$ & 19.4 \\
\hline Mir et al., 2012 [8] & 461 & NR & NR & $\begin{array}{l}\text { NR } \\
0.099\end{array}$ & $\begin{array}{l}\text { Drazil } \\
\text { Pakistan }\end{array}$ & $\mathrm{NR}$ & $\begin{array}{l}100 \\
\mathrm{NR}\end{array}$ & NR & $\begin{array}{l}1127.3 \\
\mathrm{NR}\end{array}$ & $\begin{array}{l}12.5 \\
\mathrm{NR}\end{array}$ & $\begin{array}{l}12.1 \\
\mathrm{NR}\end{array}$ & $\begin{array}{l}60.9 \\
\text { NR }\end{array}$ & $\begin{array}{l}48.8 \\
\mathrm{NR}\end{array}$ & $\begin{array}{l}12.3 \\
\text { NR }\end{array}$ \\
\hline Nascimento et al., 2007 [60] & 91 & NR & NR & 0.22 & Brazil & $\mathrm{NR}$ & 100 & NR & NR & 10 & NR & NR & NR & 33 \\
\hline Okpataku, 2016 [61] & 274 & NR & 0.182 & NR & Nigeria & 43.4 & 100 & 94.9 & NR & NR & NR & NR & 67.5 & NR \\
\hline Penteado et al., 2008 [62] & 400 & NR & NR & 0.04 & Brazil & 42.2 & NR & NR & NR & NR & 12.7 & 40.5 & NR & NR \\
\hline Pinheiro et al., 2015 [63] & 114 & NR & NR & 0.04 & Brazil & NR & 100 & 62 & NR & NR & NR & NR & 38 & NR \\
\hline Rosso et al., 2016 [64] & 168 & NR & 0.226 & NR & Italy & 42.7 & $\mathrm{NR}$ & $\mathrm{NR}$ & NR & 18 & NR & NR & 65 & NR \\
\hline Souza et al., 2005 [65] & 260 & NR & NR & 0.087 & Brazil & 38.2 & 100 & 76.6 & NR & $\mathrm{NR}$ & NR & NR & 71.3 & NR \\
\hline Valway et al., 2009 [66] & 652 & 0.0987 & NR & NR & USA & 44 & 90.6 & 51.7 & NR & 13 & NR & 76 & 78.5 & NR \\
\hline 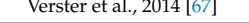 & & & 0.126 & $N R$ & The Netherlands & 33.8 & 95.6 & NR & NR & 12.6 & NR & NR & NR & NR \\
\hline
\end{tabular}

Table 5. Quality assessment of the studies included in the current meta-analysis.

\begin{tabular}{|c|c|c|c|c|c|c|c|c|c|}
\hline Study & Domain i & Domain ii & Domain iii & Domain iv & Domain $\mathbf{v}$ & Domain vi & Domain vii & Domain viii & Domain ix \\
\hline De Oliveira et al., 2016 [12] & Yes & No & Yes & Yes & Yes & Yes & Yes & Yes & Yes \\
\hline Domingos et al., 2010 [55] & Yes & No & Yes & Yes & Yes & Yes & Yes & Yes & Yes \\
\hline Girotto et al., 2015 [27] & Yes & No & Yes & Yes & Yes & Yes & Yes & Yes & Yes \\
\hline Jora et al., 2010 [56] & Yes & No & Yes & Yes & Yes & No & No & Yes & Yes \\
\hline Knauth et al., 2011 [57] & Yes & No & Yes & No & Yes & No & No & Yes & Yes \\
\hline Korelitz et al., 1993 [26] & Yes & No & Yes & No & Yes & Yes & Yes & Yes & Yes \\
\hline Laraqui et al., 2011 [58] & Yes & No & Yes & Yes & Yes & No & no & Yes & Yes \\
\hline Leopoldo et al., 2015 [59] & Yes & No & Yes & Yes & Yes & Yes & Yes & Yes & Yes \\
\hline Mir et al., 2012 [8] & Yes & Yes & Yes & No & Yes & No & No & Yes & Yes \\
\hline Nascimento et al., 2007 [60] & Yes & No & No & No & Yes & No & No & Yes & Yes \\
\hline Okpataku, 2016 [61] & Yes & Yes & Yes & Yes & Yes & Yes & Yes & Yes & Yes \\
\hline Penteado et al., 2008 [62] & Yes & No & Yes & Yes & Yes & No & No & Yes & Yes \\
\hline Pinheiro et al., 2015 [63] & Yes & No & No & Yes & Yes & No & No & Yes & Yes \\
\hline Rosso et al., 2016 [64] & Yes & No & Yes & No & Yes & Yes & Yes & Yes & Yes \\
\hline Souza et al., 2005 [65] & Yes & No & Yes & Yes & Yes & No & No & Yes & Yes \\
\hline Valway et al., 2009 [66] & Yes & No & Yes & Yes & Yes & Yes & Yes & Yes & Yes \\
\hline Verster et al., 2014 [67] & Yes & No & Yes & No & Yes & Yes & Yes & Yes & Yes \\
\hline
\end{tabular}

Domain i concerns the appropriateness of the sample frame to address the target population; Domain ii, the participants sampling technique; Domain iii, the adequateness of the sample size; Domain iv, the completeness of the description and details concerning the study subjects and the setting; Domain v, the coverage of the sample; Domain vi, the validity of the methods and Domain vii, their reliability; Domain viii, the appropriateness of the statistical analyses; and Domain ix, the adequateness of the response rate. 


\subsection{Systematic Review and Meta-Analysis of Alcohol Consumption Rates among Truck Drivers}

The total study population comprised 11,574 truck drivers, with sample sizes ranging from 91 to 2945 participants. Mean age ranged from 33.8 to 44.0 years old. Male percentage went from $89.0 \%$ to $100.0 \%$. Ten studies were performed in Brazil, whereas two studies were carried out in the USA. The remaining studies were conducted in Morocco (one study), the Netherlands (one study), Italy (one study), Nigeria (one study) and Pakistan (one study). Mean work-load ranged from 11.1 to $12.7 \mathrm{~h}$ per day and was reported only in four studies. Night-shifters (reported in four studies) varied from $12.5 \%$ to $33.0 \%$ of participants. Schooling level was described in ten studies: primary education was achieved by $30.8-81.0 \%$ of participants, according to the study. Experience years went from 10.0 to 18.1 years (reported in eight studies). Only three studies reported the percentage of truck drivers working for companies (range 40.5-60.9\%).

\subsection{Binge Drinking among Truck Drivers}

Five studies reported data concerning binge drinking among truck drivers. Based on the $I^{2}$ value (95.33), a random-effects model was performed. A rate of $19.0 \%, 95 \%$ CI $(13.1,26.9)$ was found (Figure 2, showing the forest plot). At the meta-regression analysis, country resulted a statistically significant moderator (intercept $=-1.26$, standard error $=0.17,95 \% \mathrm{CI}(-1.60,-0.92), z$-value $=-7.23$, $p=0.0000$, variance inflation factor or VIF $=1.24$; Country $=-0.96$, standard error $=0.39,95 \% \mathrm{CI}$ $(-1.73,-0.18), z$-value $=-2.42, p=0.0154, \mathrm{VIF}=1.00)$ (Figure 3). Marriage was another significant moderator (intercept $=-4.10$, standard error $=0.75(95 \% \mathrm{CI}-5.56$ to -2.63$), z$-value $=-5.49, p=0.0000$, $\mathrm{VIF}=44.73$; marriage $=0.04$, standard error $=0.01,95 \% \mathrm{CI}(0.02,0.06), z$-value $=3.42, p=0.0006$, $\mathrm{VIF}=1.00)$ (Figure 4). No other statistically significant moderators could be detected. No evidence of publication bias could be found, both visually inspecting the funnel plot (Figure 5) and conducting the Duval and Tweedie's trim-and-fill analysis, while the Egger's linear regression test (intercept $=-21.65$, standard error $=6.37,95 \% \mathrm{CI}(-41.91,-1.40), p=0.04241$ ) yielded the statistical significance (Table 6).

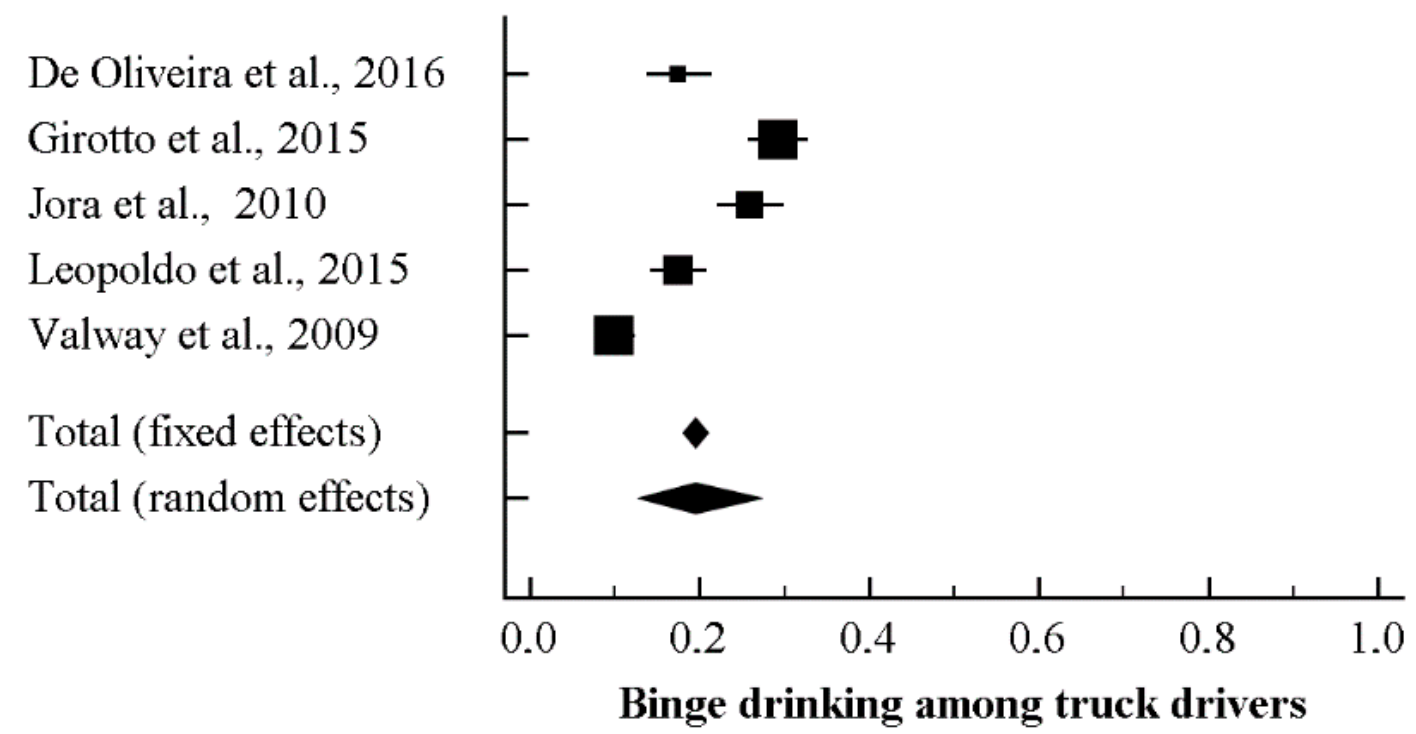

Figure 2. Forest plot for binge drinking among truck-drivers. 


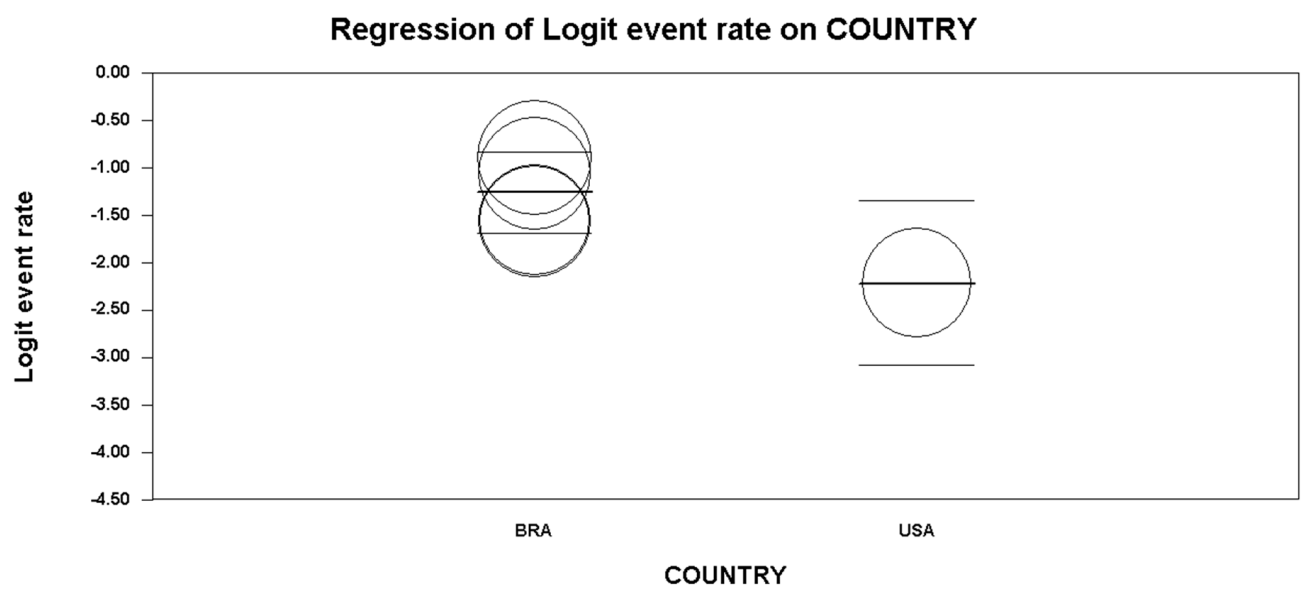

Figure 3. Meta-regression analysis showing statistically significant different binge drinking patterns in Brazil (BRA) and in the United States (USA), among truck-drivers.

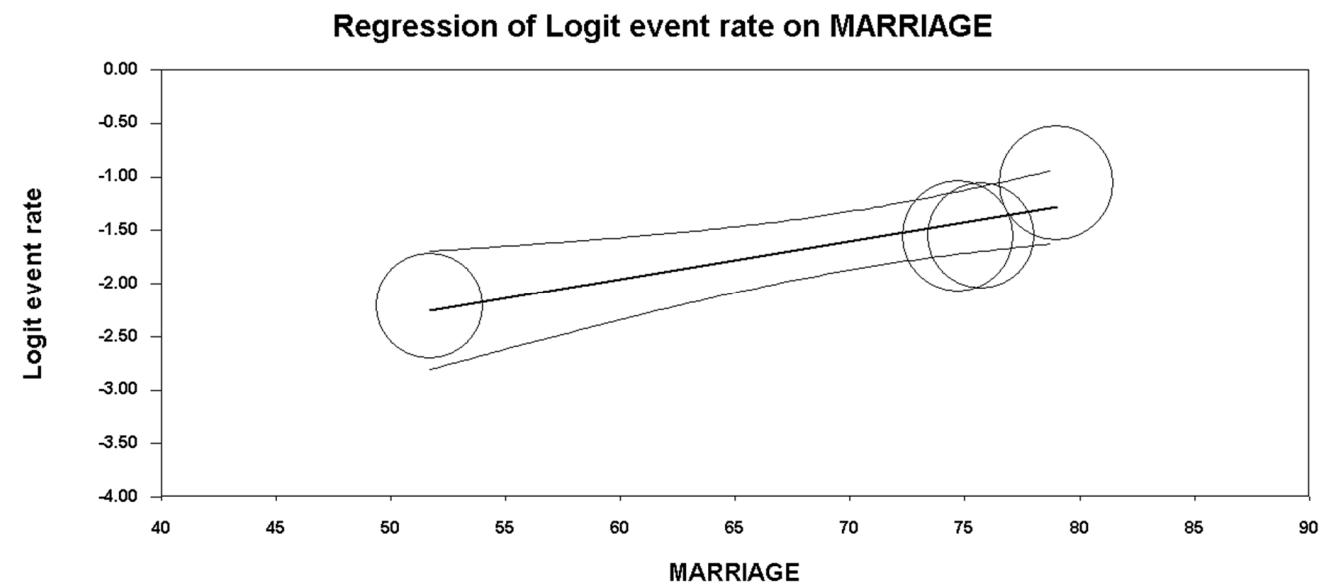

Figure 4. Meta-regression analysis for marriage (in percentage) among truck-drivers, showing that there is a statistically significant association between marital status and binge drinking (i.e., a higher marriage percentage correlated with a lower binge drinking pattern rate).

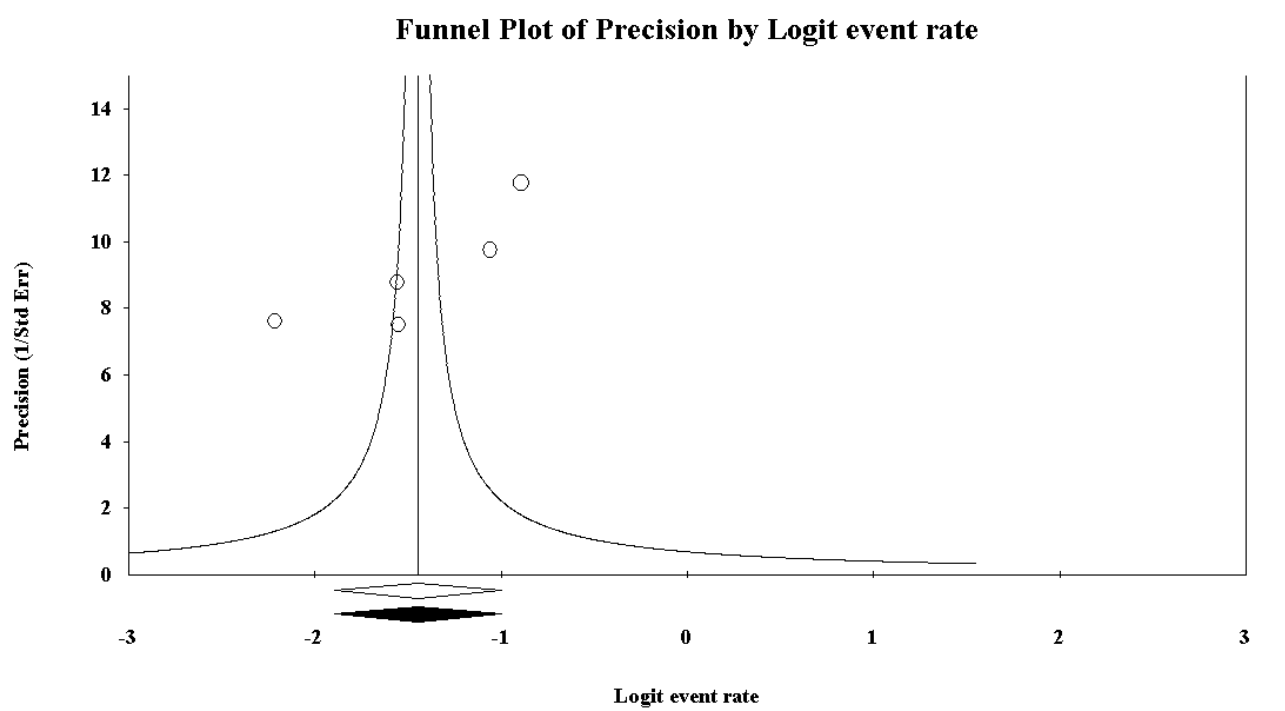

Figure 5. Funnel plot for binge drinking among truck-drivers, showing no evidence of publication bias. 
Table 6. Duval and Tweedie's trim-and-fill analysis for binge drinking rate among truck drivers.

\begin{tabular}{cccccc}
\hline & \multicolumn{3}{c}{ Random-Effects Model } & \multirow{2}{*}{$Q$ Value } \\
\cline { 1 - 5 } & Studies Trimmed & Point Estimate & Lower Limit & Upper Limit & \\
\cline { 1 - 5 } Observed values & & 0.19 & 0.13 & 0.27 & 85.55 \\
Adjusted values & 0 & 0.19 & 0.13 & 0.27 & 85.55 \\
\hline
\end{tabular}

\section{3. "Everyday Drinking" Pattern among Truck Drivers}

Seven studies reported data concerning "everyday drinking" consumption rate among truck drivers (total population 4314 subjects, ranging from 91 to 2134 participants). Based on the $I^{2}$ value (84.40), random-effects model was utilized. A rate of $9.4 \%, 95 \%$ CI $(7.0,12.4)$ was found (Figure 6). Sensitivity and cumulative analyses confirmed the stability of the findings. No statistically significant moderators were computed. Concerning the funnel plot (Figure 7), no evidence of publication bias could be detected, both visually inspecting the graph and performing the Duval and Tweedie's trim-and-fill analysis and the Egger's linear regression test (intercept $=-1.98$, standard error $=1.76$, $95 \%$ CI $(-6.51,2.54), t$-value $=1.13, p=0.31111)($ Table 7$)$.

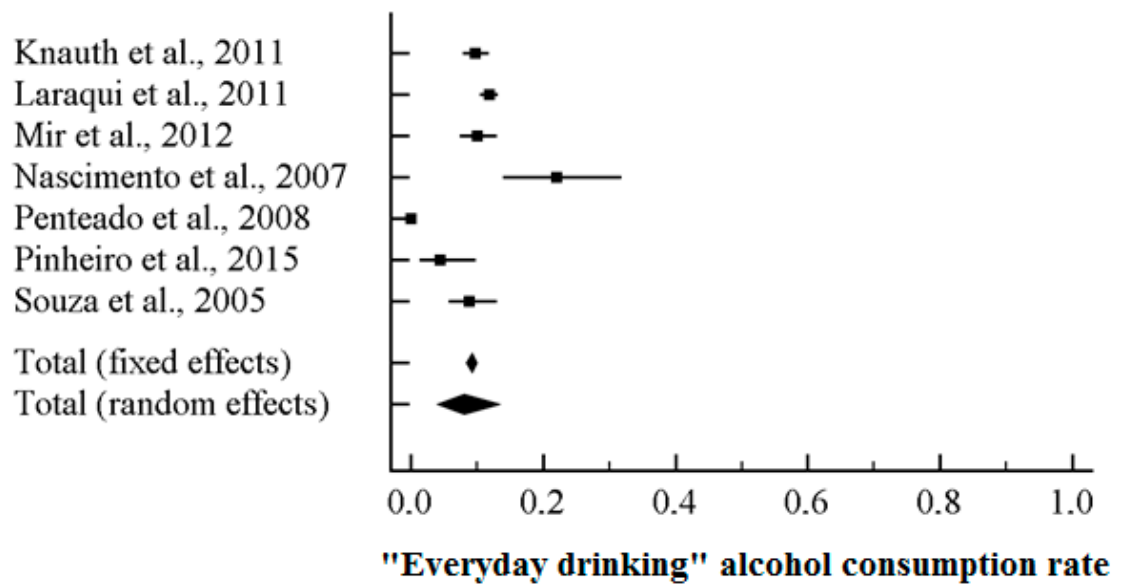

Figure 6. Forest plot for "everyday drinking" consumption rate among truck-drivers.

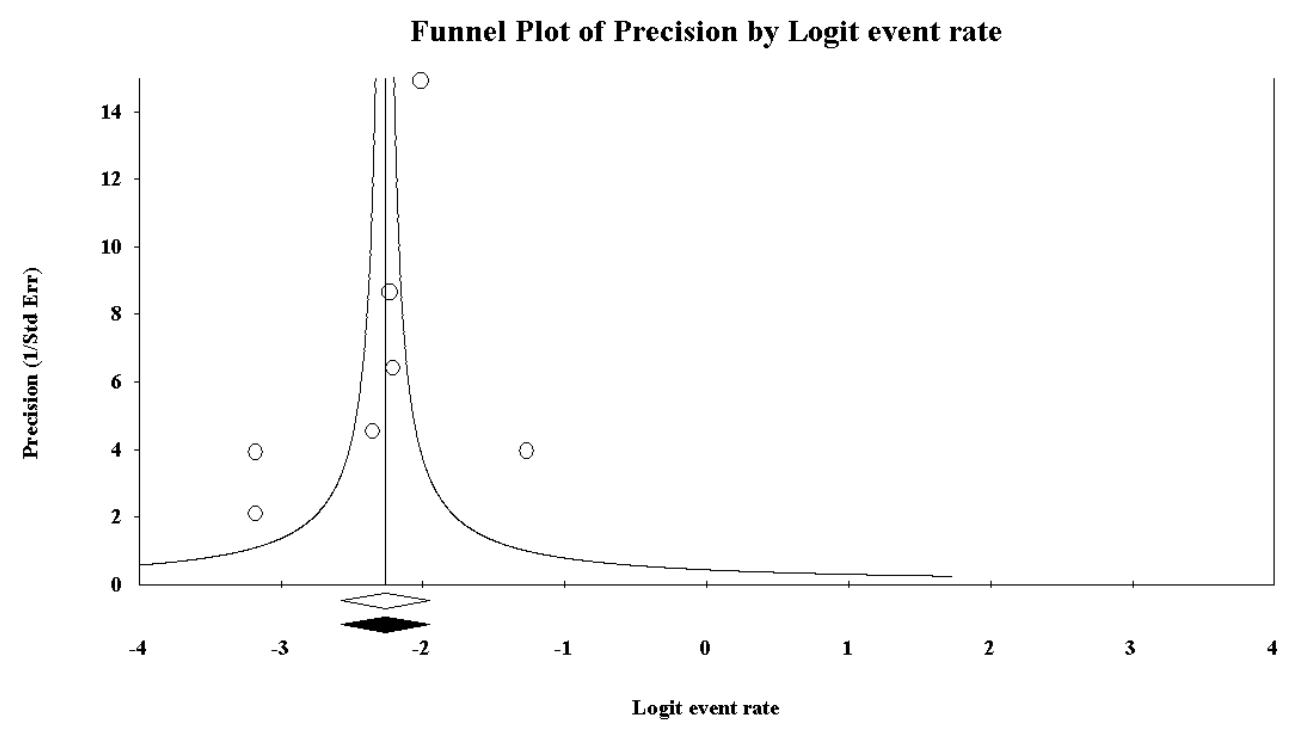

Figure 7. Funnel plot for "everyday drinking" consumption rate among truck-drivers, showing no evidence of publication bias. 
Table 7. Duval and Tweedie's trim-and-fill analysis for "everyday drinking" consumption rate among truck drivers.

\begin{tabular}{cccccc}
\hline & & \multicolumn{3}{c}{ Random-Effects Model } & \multirow{2}{*}{$Q$ Value } \\
\hline & Studies Trimmed & Point Estimate & Lower Limit & Upper Limit & \\
\hline Observed values & & 0.09 & 0.07 & 0.12 & 38.45 \\
Adjusted values & 0 & 0.09 & 0.07 & 0.12 & 38.45 \\
\hline
\end{tabular}

\subsection{Alcohol Consumption Rate among Truck Drivers Based on AUDIT-CAGE Instruments}

Five studies reported data concerning alcohol consumption rate based on AUDIT-CAGE instruments. Based on the $I^{2}$ value (97.29), random-effects model was carried out. A consumption rate of $22.7 \%, 95 \%$ CI $(14.8,33.0)$ was found (Figure 8). Concerning the funnel plot (Figure 9), no evidence of publication bias could be found, both visually inspecting the graph and carrying out the Duval and Tweedie's trim-and-fill analysis and the Egger's linear regression test (intercept $=-1.84$, standard error $=5.72,95 \%$ CI $(-20.04,16.36), t$-value $=0.32, p=0.76889)($ Table 8$)$.

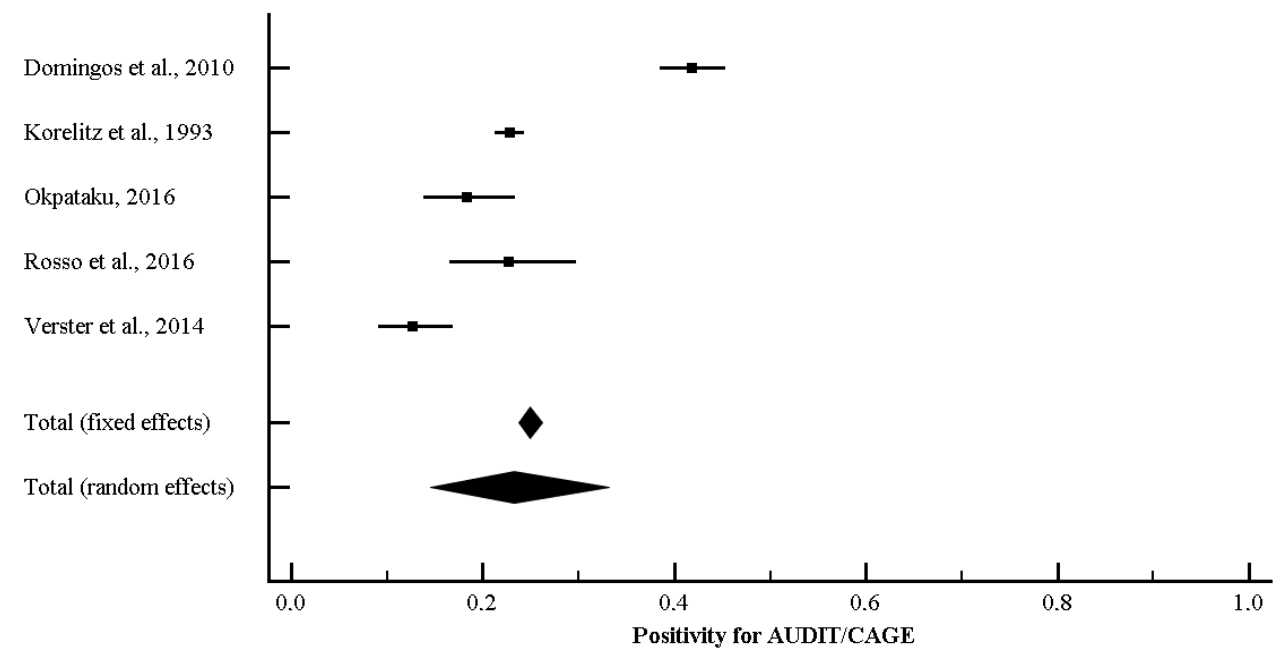

Figure 8. Forest plot for positivity to AUDIT-CAGE instruments rate among truck-drivers.

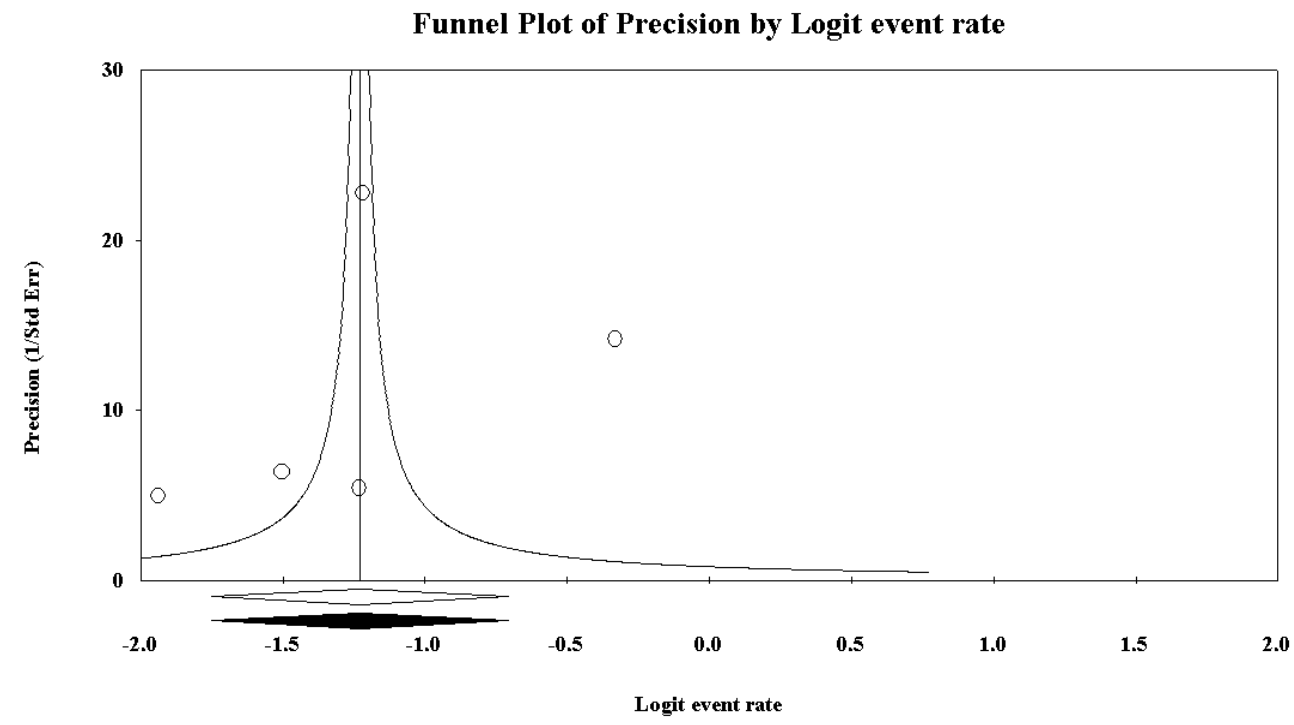

Figure 9. Funnel plot for alcohol consumption rate among truck-drivers based on the AUDIT-CAGE instruments, showing no evidence of publication bias. 
Table 8. Duval and Tweedie's trim-and-fill analysis for alcohol consumption rate among truck-drivers based on the AUDIT-CAGE instruments.

\begin{tabular}{cccccc}
\hline & & \multicolumn{3}{c}{ Random-Effects Model } & \multirow{2}{*}{$Q$ Value } \\
\hline & Studies Trimmed & Point Estimate & Lower Limit & Upper Limit & \\
\hline Observed values & & 0.23 & 0.15 & 0.33 & 147.59 \\
Adjusted values & 0 & 0.23 & 0.15 & 0.33 & 147.59 \\
\hline
\end{tabular}

\section{Discussion}

The goal of this study was to assess the harmful alcohol consumption in the occupational category of truck drivers, a group of workers of the utmost importance for road safety and the global economy. In particular, we investigated three patterns of alcohol use considered hazardous or harmful: namely, "binge drinking", "everyday drinking", and positivity to AUDIT or CAGE tests.

The findings of the current meta-analysis showed a relevant harmful alcohol use prevalence among truck drivers. The results regarding "binge drinking" (prevalence of 19.0\%) are extremely important because this mode of consumption has been linked to impairment in several executive cognitive functions $[84,85]$ necessary for the complex task of driving. Frontal executive functioning of the brain is part of a system that controls the hierarchical order of brain processing, thus permitting control over cognition and behaviors [86,87]. Some authors have suggested that this executive impairment could impact on the predisposition towards the development of harmful habits including alcohol use disorders (AUD) $[88,89]$ and use of illicit drugs. Moreover, this pattern has been associated with relevant road safety issues: "binge drinking" at least once a month increases the chance of being involved in crash accidents by ten-fold [90].

Interestingly, the results of the present study show a positive association between binge drinkers and nationality: the study showed that Brazilian drivers have a higher prevalence of "binge drinking" compared to their North American counterparts. This is comprehensible since alcohol consumption is, and has been, part of human culture, with different historical and social significance, as well as characterized by diverse patterns of consumption and different legislation in every country. Nevertheless, this observation needs further data: most studies that evaluated "binge drinking" were performed in Brazil, while only one was performed in the USA.

Another association was found between "binge drinking" and marriage. Since most truck drivers spend significant amounts of time away from home, days and even weeks at a time, this result can be interpreted—as some authors have suggested—that being distant from families removes a valuable support system that acts as a barrier against stress [28].

Regarding the "everyday drinking" pattern, our results showed a prevalence of $9.4 \%$ in the studied population. This issue is particularly relevant for the specific occupational category of truck drivers, a group of workers that most likely drives every working day. Among drivers drinking everyday could be indicative of another alcohol use pattern: AUDs [57]. Indeed, "everyday drinking" puts the user on the threshold of at risk consumption even considering the AUDIT test.

Another important finding of the present study is the prevalence of positives to AUDIT-CAGE tests $(22.7 \%)$. Although this significant prevalence, and despite the fact that the AUDIT instrument is a reliable and easy to use test, the real epidemiological figures could be even higher, in light of under-reporting during the Occupational Health Surveillance, as suggested by some authors [61].

Moreover, an association between testing positive and being overweight or obese has been reported in the literature [52]. It is well known that excess bodyweight is one of the major risk factors for OSA. Therefore it is not surprising that OSA is more prevalent in truck drivers than the general population [91]. Statistically significant rise in sleep apnea severity and cardiac frequency are induced by $0.5 \mathrm{~g}$ alcohol $/ \mathrm{kg}$ body weight, a level regarded as the safe upper limit by health authorities, on sleep apnea in otherwise healthy habitual snorers with mild-to-moderate OSA [92]. Similar results were obtained in a truck driver sample [72,73]. 
Even if heterogeneity exists between countries worldwide, the results discussed above show various prevalence rates among truck drivers, approximately in line with the prevalence in the general population, as reported in Table 9.

Table 9. Alcohol consumption in the general population 15+ years old.

\begin{tabular}{ccc}
\hline Country & $\begin{array}{c}\text { Harmful Consumption Rate (Risk } \\
\text { Drinking, Heavy Episodic Drinking) }\end{array}$ & Consumption Rate in the Past 12 Months \\
\hline EU27 2010 (Eurobarometer) [93] & $32.7 \%$, past month & $76 \%$ \\
Italy 2016 (National Institute of Statistics or ISTAT) [94] & $15.9 \%$, past year & $64.7 \%$ \\
Brazil 2010 (WHO), male [9] & $20.7 \%$, past month & $69.3 \%$ \\
USA 2015 (National Survey on Drug Use and Health or & $26.9 \%$, past month & $70.1 \%$ \\
NSUDH) [95] & $10.5 \%$, past month & $92.9 \%$ \\
The Netherlands 2010 (WHO), male [9] & & \\
\hline
\end{tabular}

Many countries and international organizations have implemented policies aimed at reducing alcohol use among the general population. One of the guiding principles of the global strategy to reduce alcohol consumption adopted by the WHO is the "protection of populations at high risk of alcohol-attributable harm and those exposed to the effects of harmful drinking by others should be an integral part of policies addressing the harmful use of alcohol" [96]. The "European action plan to reduce the harmful use of alcohol 2012-2020" suggests a development of community and workplace resources for alcohol programs, and an enhanced enforcement of road alcohol tests as well as a reduction of the blood-alcohol content [97].

In Italy, the Prevention National Plan 2014-2018 [98] regards the prevention of substance use, the prevention of traffic accidents, and the prevention of occupational injuries and disorders as three of its ten macro-goals. It is thus clear that the issue is of importance both from a public health as well as from an occupational health perspective. However, there are several factors among truck drivers that must be accounted for: truck drivers are one of the occupational categories identified by the State-Regions Conference in 2006 as at high risk of injuries and harm to others, to which the sale and use of alcohol is prohibited. Furthermore, Italian driving law requires a total absence of blood alcohol concentration $(0 \mathrm{~g} / \mathrm{L})$ for professional drivers (the so-called "zero effective tolerance" policy), while the threshold for the general population is $0.5 \mathrm{~g} / \mathrm{L}$. Not all countries have adopted such policy and, as such, the alcohol level at which a person is considered legally impaired differs among countries.

A combined effect of a low quantity of alcohol with moderate sleep restriction results in significant decrements to subjective alertness and driving performance [99]. The detrimental effect of alcohol is also observed in relation to circadian sleep propensity. Even low consumption of alcohol could be too high when driving under a condition of increased sleep pressure such as during the night hours, in association to the effect of sleep deprivation. The highest values of hourly circadian sleep propensity are during the night, with a secondary maximum in the afternoon. Due to the significant interaction, even low BAC levels strongly increased road accident risk when associated with high sleep propensity [100].

Managing the issue of alcohol use among truck drivers is therefore bidirectional: public health policies can help reduce the consumption rate also among truck drivers, while occupational health prevention and health promotion will contribute to the reduction in the general population consumption. The first necessary step is to further study the epidemiology, especially in Europe, in order to better grasp the current state of the problem, with the aim of filling the current gap of knowledge supporting policy makers in implementing effective measures to contrast it.

\section{Strengths and Weaknesses}

To the best of the authors' knowledge, this is the first systematic review and meta-analysis studying alcohol consumption in truck drivers. The strengths of this study include comprehensive coverage of the literature, careful appraisal of study quality, risk of bias, consideration of possible 
subgroup effects, and a focus on relevant endpoints to this specific occupational category. However, this study also presented a few shortcomings.

One of the major limitations of this meta-analysis was the paucity of studies, especially from Europe. This finding is even more relevant if we consider that this region has the highest per capita alcohol consumption and alcohol-attributable disease burden reported in the world. Moreover, there is a high level of "binge drinking" among Europeans, as it is apparent from Table 9. There is a dearth of studies on truck drivers in European countries, for which no/little current epidemiological data are available, which means de facto ignoring the potential risk represented by harmful drinking pattern in this occupational category.

Such a geographical disparity might have influenced the results of the meta-analysis because of different socio-economic contexts and cultural backgrounds. Another important limitation in this study was the qualitative differences concerning the way of collecting data on alcohol use and the demographics of the population between studies.

Several studies had to be excluded from the meta-analysis because data on alcohol consumption in frequency/dose were missing, or because data were related to any consumption pattern in the past 12 months. Another limitation regarded the quantity and quality of the studies assessing the consumption during working hours using biological sampling: although seven studies evaluated alcohol content in bodily fluids, each one used different detection methods and cut-offs. In our assessment, only blood samples or breath correlates are indicative of recent alcohol use. Positive results in urine and saliva tests might be detected even after $48-72 \mathrm{~h}$ after alcohol consumption. Finally, as already mentioned in the material and methods section, caution should be taken in interpreting the findings of the statistical tests used for assessing the publication bias, given the high heterogeneity and the small number of included studies.

An improvement over these limitations is needed in order to better understand and evaluate the issue of alcohol use among truck drivers with a higher degree of accuracy. More studies using standardized questionnaires-thoroughly investigating the demographics, psycho-social determinants of the population, and well-defined patterns of alcohol use-need to be performed. Also, studies using comparable biological sampling methodologies are necessary.

\section{Conclusions}

This systematic review with meta-analysis provides the first rigorous analytical synthesis of updated epidemiological data regarding truck drivers. Our findings show that the prevalence of alcohol use among this occupational category can be considered harmful and put the light on some existing gaps, including the dearth of studies and data for many countries, but at the same time provide useful insights. This can be useful for decision and policy-makers in order to develop, design, and implement adequate surveillance and preventive policies.

However, in order to better assess the magnitude of the risk, more specified and defined modes of consumption must be investigated.

Author Contributions: N.L.B. and P.D. conceived and designed the experiments; N.L.B. performed the experiments; N.L.B. analyzed the data; N.L.B., G.D., A.T., A.R., A.M., E.M., A.M.., O.G., S.G., N.D., and P.D. wrote the paper.

Acknowledgments: No funding was received for this study.

Conflicts of Interest: The authors declare no conflict of interest.

\section{References}

1. Brady, J.E.; Li, G. Trends in alcohol and other drugs detected in fatally injured drivers in the United States, 1999-2010. Am. J. Epidemiol. 2014, 179, 692-699. [CrossRef] [PubMed]

2. Roche, A.M.; Pidd, K.; Berry, J.G.; Harrison, J.E. Workers' drinking patterns: The impact on absenteeism in the Australian work-place. Addiction 2008, 103, 738-748. [CrossRef] [PubMed] 
3. Goetzel, R.Z.; Long, S.R.; Ozminkowski, R.J.; Hawkins, K.; Wang, S.; Lynch, W. Health, absence, disability, and presenteeism cost estimates of certain physical and mental health condition affecting U.S. employers. J. Occup. Environ. Med. 2004, 46, 398-412. [CrossRef] [PubMed]

4. Spicer, R.S.; Miller, T.R.; Smith, G.S. Worker substance use, workplace problems and the risk of occupational injury: A matched case-control study. J. Stud. Alcohol 2003, 64, 570-578. [CrossRef] [PubMed]

5. McNeilly, B.; Ibrahim, J.E.; Bugeja, L.; Ozanne-Smith, J. The prevalence of work-related deaths associated with alcohol and drugs in Victoria, Australia, 2001-6. Inj. Prev. 2010, 16, 423-428. [CrossRef] [PubMed]

6. Bamberger, P.A.; Cohen, A. Driven to the bottle work-related risk factors and alcohol misuse among commercial drivers. J. Drug Issues 2015, 45, 180-201. [CrossRef]

7. Connor, J.; Norton, R.; Ameratunga, S.; Jackson, R. The contribution of alcohol to serious car crash injuries. Epidemiology 2004, 15, 337-344. [CrossRef] [PubMed]

8. Mir, M.U.; Khan, I.; Ahmed, B.; Abdul Razzak, J. Alcohol and marijuana use while driving-an unexpected crash risk in Pakistani commercial drivers: A cross-sectional survey. BMC Public Health 2012, 12, 145. [CrossRef] [PubMed]

9. World Health Organization (WHO). Global Status Report on Alcohol and Health 2014. Available online: http:/ /apps.who.int/iris/bitstream/handle/10665/112736/9789240692763_eng.pdf;jsessionid= 9FA8EF583DFA9DE898718C9153937514? sequence=1 (accessed on 11 April 2018).

10. World Health Organization (WHO). Global Status Report on Road Safety 2015. Available online: http: / /apps.who.int/iris/bitstream/10665/189242/1/9789241565066_eng.pdf?ua=1 (accessed on 11 April 2018).

11. World Health Organization (WHO). Global Status Report on Road Safety 2013: Supporting a Decade of Action. Available online: http:/ / apps.who.int/iris/bitstream/handle/10665/78256/9789241564564_eng. pdf?sequence $=1 \&$ is Allowed $=y$ (accessed on 11 April 2018).

12. De Oliveira, L.G.; Leopoldo, K.; Gouvea, M.J.; Barroso, L.P.; Gouveia, P.A.; Muñoz, D.R.; Leyton, V. Prevalence of at-risk drinking among Brazilian truck drivers and its interference on the performance of executive cognitive tasks. Drug Alcohol Depend. 2016, 166, 218-225. [CrossRef] [PubMed]

13. U.S. Department of Labor, Bureau of Labor Statistics. Occupation Employment Statistics 2017. Available online: https:/ / www.bls.gov/oes/oes_doc.htm (accessed on 10 March 2018).

14. Australian Bureau of Statistics. Business Transport Activity. Available online: http://www.abs.gov.au/ ausstats/abs@.nsf/Lookup/9269.0main+features52010--11 (accessed on 10 March 2017).

15. Statistical Office of the European Communities. Employment in Goods Road Transport Enterprises. Last Update: 28 October 2015. Available online: http:/ /appsso.eurostat.ec.europa.eu/nui/show.do?dataset= road_ec_empl\&lang=en (accessed on 10 March 2018).

16. Girotto, E.; Mesas, A.E.; de Andrade, S.M.; Birolim, M.M. Psychoactive substance use by truck drivers: A systematic review. Occup. Environ. Med. 2014, 71, 71-76. [CrossRef] [PubMed]

17. Criezzle, A.M.; Bigelow, P.; Adams, D.; Gooderham, S.; Myers, A.M.; Thiffault, P. Health and wellness of long-haul truck drivers and bus drivers: A systematic review and directions for future researches. J. Transp. Health 2017, 7, 90-109. [CrossRef]

18. Apostolopoulos, Y.; Sönmez, S.; Shattell, M.M.; Belzer, M. Worksite-induced morbidities among truck drivers in the United States. AAOHNJ 2010, 58, 285-296. [CrossRef] [PubMed]

19. Sadeghniiat-Haghighi, K.; Yazdi, Z. Fatigue management in the workplace. Ind. Psychiatry J. 2015, $24,12-17$. [PubMed]

20. Guglielmi, O.; Magnavita, N.; Garbarino, S. Sleep quality, obstructive sleep apnea, and psychological distress in truck drivers: A cross-sectional study. Soc. Psychiatry Psychiatr. Epidemiol. 2017. [CrossRef] [PubMed]

21. Burns, N. An integrative review of screening for obstructive sleep apnea in commercial vehicle drivers. Workplace Health Saf. 2014, 62, 114-120. [CrossRef] [PubMed]

22. Cashman, C.M.; Ruotsalainen, J.H.; Greiner, B.A.; Beirne, P.V.; Verbeek, J.H. Alcohol and drug screening of occupational drivers for preventing injury. Cochrane Database Syst. Rev. 2009, 15, CD006566. [CrossRef] [PubMed]

23. Gamble, J.F.; Nicolich, M.J.; Boffetta, P. Lung cancer and diesel exhaust: An updated critical review of the occupational epidemiology literature. Crit. Rev. Toxicol. 2012, 42, 549-598. [CrossRef] [PubMed]

24. Marqueze, E.C.; Ulhôa, M.A.; Moreno, C.R. Irregular working times and metabolic disorders among truck drivers: A review. Work 2012, 41, 3718-3725. [PubMed] 
25. Zhang, X.; Chow, E.P.; Wilson, D.P.; Sun, X.; Zhao, R.; Zhang, J.; Jing, J.; Zhang, L. Prevalence of HIV and syphilis infections among long-distance truck drivers in China: A data synthesis and meta-analysis. Int. J. Infect. Dis. 2013, 17, e2-e7. [CrossRef] [PubMed]

26. Korelitz, J.J.; Fernandez, A.A.; Uyeda, V.J.; Spivey, G.H.; Browdy, B.L.; Schmidt, R.T. Health habits and risk factors among truck drivers visiting a health booth during a trucker trade show. Am. J. Health Promot. 1993, 8, 117-123. [CrossRef] [PubMed]

27. Girotto, E.; de Andrade, S.M.; Mesas, A.E.; González, A.D.; Guidoni, C.M. Working conditions and illicit psychoactive substance use among truck drivers in Brazil. Occup. Environ. Med. 2015, 72, 764-769. [CrossRef] [PubMed]

28. Gay Anderson, D.; Riley, P. Determining standards of care for substance abuse and alcohol use in long-haul truck drivers. Nurs. Clin. N. Am. 2008, 43, 357-365. [CrossRef] [PubMed]

29. Garbarino, S.; Durando, P.; Guglielmi, O.; Dini, G.; Bersi, F.; Fornarino, S.; Toletone, A.; Chiorri, C.; Magnavita, N. Sleep apnea, sleep debt and daytime sleepiness are independently associated with road accidents. A cross-sectional study on truck drivers. PLoS ONE 2016, 11, e166262. [CrossRef] [PubMed]

30. Garbarino, S.; Magnavita, N.; Guglielmi, O.; Maestri, M.; Dini, G.; Bersi, F.M.; Toletone, A.; Chiorri, C.; Durando, P. Insomnia is associated with road accidents. Further evidence from a study on truck drivers. PLoS ONE 2017, 12, e0187256. [CrossRef] [PubMed]

31. Hege, A.; Apostolopoulos, Y.; Perko, M.; Sönmez, S.; Strack, R. The work organization of long-haul truck drivers and the association with body mass index. J. Occup. Environ. Med. 2016, 58, 712-717. [CrossRef] [PubMed]

32. Wagstaff, A.S.; Sigstad Lie, J.A. Shift and night work and long working hours-A systematic review of safety implications. Scand. J. Work Environ. Health 2011, 37, 173-185. [CrossRef] [PubMed]

33. Virtanen, M.; Jokela, M.; Nyberg, S.T.; Madsen, I.E.; Lallukka, T.; Ahola, K.; Alfredsson, L.; Batty, G.D.; Bjorner, J.B.; Borritz, M.; et al. Long working hours and alcohol use: Systematic review and meta-analysis of published studies and unpublished individual participant data. BMJ 2015, 350, g7772. [CrossRef] [PubMed]

34. Leyton, V.; Sinagawa, D.M.; Oliveira, K.C.; Schmitz, W.; Andreuccetti, G.; De Martinis, B.S.; Yonamine, M.; Munoz, D.R. Amphetamine, cocaine and cannabinoids use among truck drivers on the roads in the State of Sao Paulo, Brazil. Forensic Sci. Int. 2012, 215, 25-27. [CrossRef] [PubMed]

35. Copello, F.; Garbarino, S.; Messineo, A.; Campagna, M.; Durando, P.; Collaborators. Occupational Medicine and Hygiene: Applied research in Italy. J. Prev. Med. Hyg. 2015, 56, E102-E110. [PubMed]

36. Mabbott, N.A.; Hartley, L.R. Patterns of stimulant drug use on Western Australian heavy transport routes. Transport. Res. Part F2 1999, 115-130. [CrossRef]

37. Verstraete, A.G.; Pierce, A. Workplace drug testing in Europe. Forensic Sci. Int. 2001, 121, 2-6. [CrossRef]

38. Drummer, O.H.; Gerostamoulos, J.; Batziris, H.; Chu, M.; Caplehorn, J.; Robertson, M.D.; Swann, P. The involvement of drugs in drivers of motor vehicles killed in Australian road traffic crashes. Accid. Anal. Prev. 2004, 36, 239-248. [CrossRef]

39. Drummer, O.H.; Gerostamoulos, J.; Batziris, H.; Chu, M.; Caplehorn, J.R.; Robertson, M.D.; Swann, P. The incidence of drugs in drivers killed in Australian road traffic crashes. Forensic Sci. Int. 2003, 134, 154-162. [CrossRef]

40. Haguenoer, J.M.; Hannothiaux, M.H.; Lahaye-Roussel, M.C.; Fontaine, B.; Legrand, P.M. Prévalence des comportements toxicophiles en milieu professionnel: Une étude dans la région Nord Pas de Calais. Bull. l'Ordre Médecins 1997, 80, 11-15.

41. Constant, P. Workplace drug testing: The Esso/Exxon 10 years experience. Presentation Given at the Second European Symposium on Workplace Drug Testing, Rimini, Italy, 2000.

42. George, S. A snapshot of workplace drug testing in the UK. Occup. Med. 2005, 55, 69-71. [CrossRef] [PubMed]

43. World Health Organization (WHO), Regional Office for Europe. Alcohol in the European Union. Consumption, Harm and Policy Approaches 2012. Available online: http:/ / www.euro.who.int/_data/ assets / pdf_file/0003/160680/e96457.pdf?ua=1 (accessed on 11 April 2018).

44. European Foundation for the Improvement of Living and Working Conditions (Eurofound), European Union. Use of Alcohol and Drugs at the Workplace 2012. Available online: https: / www.eurofound.europa. eu/sites/default/files/ef_files/docs/ewco/tn1111013s/tn1111013s.pdf (accessed on 11 April 2018). 
45. International Labour Organization (ILO). Management of Alcohol- and Drug-Related Issues in the Workplace 1996. Available online: http:/ /www.ilo.org/wcmsp5/groups/public/---ed_protect/---protrav/ ---safework/documents/normativeinstrument/wcms_107799.pdf (accessed on 11 April 2018).

46. Magnavita, N.; De Lorenzo, G.; Gailo, M.; Garbarino, S.; Goggiomani, A.; Janiri, L.; Messineo, A.; Miggiano, G.; Pichini, S.; Porpora, A.; et al. Alcohol and work. Consensus document of the La.R.A. (workers representing a risk for others group). Med. Lav. 2014, 105, 3-86. [PubMed]

47. Shamseer, L.; Moher, D.; Clarke, M.; Ghersi, D.; Liberati, A.; Petticrew, M.; Shekelle, P.; Stewart, L.A.; PRISMA-P Group. Preferred reporting items for systematic review and meta-analysis protocols (PRISMA-P) 2015: Elaboration and explanation. BMJ 2015, 349, g7647. [CrossRef] [PubMed]

48. Chien, P.F.; Khan, K.S.; Siassakos, D. Registration of systematic reviews: PROSPERO. BJOG 2012, 119, 903-905. [CrossRef] [PubMed]

49. Bragazzi, N.L.; Dini, G.; Toletone, A.; Durando, P. An Updated Systematic Review with Meta-Analysis Examining Prevalence of Drugs and Alcohol Use among Truck-Drivers. PROSPERO 2016: CRD42016037077. Available online: http://www.crd.york.ac.uk/PROSPERO/display_record.asp?ID=CRD42016037077 (accessed on 11 April 2018).

50. Moher, D.; Liberati, A.; Tetzlaff, J.; Altman, D.G.; PRISMA Group. Preferred reporting items for systematic reviews and meta-analyses: The PRISMA Statement. Open Med. 2009, 3, e123-e130. [PubMed]

51. Higgins, J.P.; Thompson, S.G. Quantifying heterogeneity in a meta-analysis. Stat. Med. 2002, 21, 1539-1558. [CrossRef] [PubMed]

52. Huedo-Medina, T.B.; Sánchez-Meca, J.; Marín-Martínez, F.; Botella, J. Assessing heterogeneity in meta-analysis: Q statistic or I2 index? Psychol. Methods 2006, 11, 193-206. [CrossRef] [PubMed]

53. Duval, S.; Tweedie, R. Trim and fill: A simple funnel-plot-based method of testing and adjusting for publication bias in meta-analysis. Biometrics 2000, 56, 455-463. [CrossRef] [PubMed]

54. Egger, M.; Davey Smith, G.; Schneider, M.; Minder, C. Bias in meta-analysis detected by a simple, graphical test. BMJ 1997, 315, 629-634. [CrossRef] [PubMed]

55. Domingos, J.B.C.; Jora, N.P.; Carvalho, A.M.P.; Pillon, S.C. Consumo de álcool, sobrepeso e obesidade entre caminhoneiros. Rev. Enferm. 2010, 18, 377-382.

56. Jora, N.P.; Magalhães, T.R.; Domingos, J.B.C.; Pillon, S.C. Campanha saúde na estrada: Avaliação do padrão de consumo de álcool e estresse. Revista Eletrônica de Enfermagem 2010, 12, 37-46. [CrossRef]

57. Knauth, D.R.; Pilecco, F.B.; Leal, A.F.; Seffner, F.; Teixeira, A.M. Staying awake: truck drivers' vulnerability in Rio Grande do Sul, Southern Brazil. Rev. Saude Publica 2012, 46, 886-893. [CrossRef] [PubMed]

58. Laraqui, S.; Laraqui, O.; Tripodi, D.; Manar, N.; Aoudi, Y.E.; Caubet, A.; Verger, C.; Ghailan, T.; Laraqui, C.H. Prevalence and risk factors of alertness disorders of professional drivers in Morocco. Sante Publique 2011, 23, 89-100. [CrossRef] [PubMed]

59. Leopoldo, K.; Leyton, V.; Oliveira, L.G. Alcohol use alone and in combination with other drugs among truck drivers on highways in São Paulo State, Brazil: A cross-sectional study. Cad. Saude Publica 2015, 31, 1916-1928. [CrossRef] [PubMed]

60. Nascimento, E.C.; Nascimento, E.; Silva, J.P. Uso de álcool e anfetaminas entre caminhoneiros de estrada. Rev. Saúde Pública 2007, 41, 290-293. [CrossRef]

61. Okpataku, C.I. Pattern and reasons for substance use among long-distance commercial drivers in a Nigerian city. Indian J. Public Health 2015, 59, 259-263. [CrossRef] [PubMed]

62. Penteado, R.Z.; Gonçalves, C.G.O.; Costa, D.D.; Marques, J.M. Trabalho e saúde em motoristas de caminhão no interior de São Paulo. Saúde Soc. 2008, 17, 35-45. [CrossRef]

63. Pinheiro, M.L.P.; Muniz, L.F.; da Silva, M.C.V.; Resille, D.P.; Filho, P.C.P.T. Amphetamines consumption and alcohol for truck drivers. J. Nurs. UFPE On Line Recife 2015, 9, 8519-8525.

64. Rosso, G.L.; Montomoli, C.; Candura, S.M. Poor weight control, alcoholic beverage consumption and sudden sleep onset at the wheel among Italian truck drivers: A preliminary pilot study. Int. J. Occup. Med. Environ. Health 2016, 29, 405-416. [CrossRef] [PubMed]

65. Souza, J.C.; Paiva, T.; Reimão, R. Sleep habits, sleepiness and accidents among truck drivers. Arquivos de Neuro-Psiquiatria 2005, 63, 925-930. [CrossRef] [PubMed]

66. Valway, S.; Jenison, S.; Keller, N.; Vega-Hernandez, J.; Hubbard McCree, D. Risk assessment and screening for sexually transmitted infections, HIV, and hepatitis virus among long-distance truck drivers in New Mexico, 2004-2006. Am. J. Public Health 2009, 99, 2063-2068. [CrossRef] [PubMed] 
67. Verster, J.C.; Van Der Maarel, M.A.; McKinney, A.; Olivier, B.; De Haan, L. Driving during alcohol hangover among dutch professional truck drivers. Traffic Inj. Prev. 2014, 15, 434-438. [CrossRef] [PubMed]

68. de Oliveira, L.G.; de Souza, L.M.; Barroso, L.P.; Gouvêa, M.J.; de Almeida, C.V.; Muñoz, D.R.; Leyton, V. Occupational conditions and the risk of the use of amphetamines by truck drivers. Rev. Saude Publica 2015, 49, 61. [CrossRef] [PubMed]

69. Lemire, A.M.; Montégiani, M.; Dussault, C. Alcohol and drug consumption by Québec. In Proceedings of the 16th International Conference on Alcohol, Drugs and Traffic Safety, Montreal, QC, Canada, 4-9 August 2002.

70. Mansur Ade, P.; Rocha, M.A.; Leyton, V.; Takada, J.Y.; Avakian, S.D.; Santos, A.J.; Novo, G.C.; Nascimento, A.L.; Muñoz, D.R.; Rohlfs, W.J. Risk Factors for Cardiovascular Disease, Metabolic Syndrome and Sleepiness in Truck Drivers. Arq. Bras. Cardiol. 2015, 105, 560-565. [CrossRef] [PubMed]

71. Maarefvand, M.; Kassaie, B.; Ghiasvand, H.; Abolfathi Gharibdoosti, R.; Khubchandani, J. Sexual and Drug Use Risk Behaviors of Internal Long Distance Truck Drivers in Iran. Iran J. Public Health 2016, 45, 606-613. [PubMed]

72. Masson, V.A.; Monteiro, M.I. Vulnerability to sexually transmitted diseases/AIDS and use of psychoactive drugs by truck drivers. Rev. Bras. Enferm. 2010, 63, 79-83. [CrossRef] [PubMed]

73. Masson, V.A.; Monteiro, M.I. Life style, health aspects and work among truck drivers. Rev. Bras. Enferm. 2010, 63, 533-540. [CrossRef] [PubMed]

74. Riva, M.M.; Marchetti, F.A.; Giupponi, V.; Mosconi, G. Health surveillance of truck drivers: It is not just a question of drugs. Description of a one-year experience. Med. Lav. 2010, 101, 207-217. [PubMed]

75. Sakurai, S.; Cui, R.; Tanigawa, T.; Yamagishi, K.; Iso, H. Alcohol consumption before sleep is associated with severity of sleep-disordered breathing among professional Japanese truck drivers. Alcohol. Clin. Exp. Res. 2007, 31, 2053-2058. [CrossRef] [PubMed]

76. Sangaleti, C.T.; Trincaus, M.R.; Baratieri, T.; Zarowy, K.; Ladika, M.B.; Menon, M.U.; Miyahara, R.Y.; Raimondo, M.I.; Silveira, J.V.; Bortolotto, L.A.; et al. Prevalence of cardiovascular risk factors among truck drivers in the South of Brazil. BMC Public Health 2014, 14, 1063. [CrossRef] [PubMed]

77. Takitane, J.; de Oliveira, L.G.; Endo, L.G.; de Oliveira, K.C.; Muñoz, D.R.; Yonamine, M.; Leyton, V. Amphetamine use by truck drivers on highways of Sao Paulo State: A risk for the occurrence of traffic accidents? Cien. Saude Colet. 2013, 18, 1247-1254. [CrossRef] [PubMed]

78. Yonamine, M.; Sanches, L.R.; Paranhos, B.A.; de Almeida, R.M.; Andreuccetti, G.; Leyton, V. Detecting alcohol and illicit drugs in oral fluid samples collected from truck drivers in the state of São Paulo, Brazil. Traffic Inj. Prev. 2013, 14, 127-131. [CrossRef] [PubMed]

79. Gjerde, H.; Christophersen, A.S.; Normann, P.T.; Pettersen, B.S.; Sabaredzovic, A.; Samuelsen, S.O.; Mørland, J. Analysis of alcohol and drugs in oral fluid from truck drivers in Norway. Traffic Inj. Prev. 2012, 13, 43-48. [CrossRef] [PubMed]

80. Couper, F.J.; Pemberton, M.; Jarvis, A.; Hughes, M.; Logan, B.K. Prevalence of drug use in commercial tractor-trailer drivers. J. Forensic Sci. 2002, 47, 562-567. [PubMed]

81. Labat, L.; Fontaine, B.; Delzenne, C.; Doublet, A.; Marek, M.C.; Tellier, D.; Tonneau, M.; Lhermitte, M.; Frimat, P. Prevalence of psychoactive substances in truck drivers in the Nord-Pas-de-Calais region (France). Forensic Sci. Int. 2008, 174, 90-94. [CrossRef] [PubMed]

82. Woratanarat, P.; Ingsathit, A.; Suriyawongpaisal, P.; Rattanasiri, S.; Chatchaipun, P.; Wattayakorn, K.; Anukarahanonta, T. Alcohol, illicit and non-illicit psychoactive drug use and road traffic injury in Thailand: A case-control study. Accid. Anal. Prev. 2009, 41, 651-657. [CrossRef] [PubMed]

83. Lund, A.K.; Preusser, D.F.; Blomberg, R.D.; Williams, A.F. Drug use by tractor-trailer drivers. J. Forensic Sci. 1988, 33, 648-661. [CrossRef] [PubMed]

84. Oliveira, L.G.; Yonamine, M.; Andreucceti, G.; Ponce Jde, C.; Leyton, V. Alcohol and other drug use by Brazilian truck drivers: A cause for concern? Rev. Bras. Psiquiatr. 2012, 34, 116-117. [CrossRef]

85. Houston, R.J.; Derrick, J.L.; Leonard, K.E.; Testa, M.; Quigley, B.M.; Kubiak, A. Effects of heavy drinking on executive cognitive functioning in a community sample. Addict. Behav. 2014, 39, 345-349. [CrossRef] [PubMed]

86. Daffner, K.R.; Searl, M.M. The dysexecutive syndromes. Handb. Clin. Neurol. 2008, 88, 249-267. [PubMed]

87. Strauss, E.; Sherman, E.; Spreen, O. A Compendium Of Neuropsychological Tests: Administration, Norms and Commentary, 3rd ed.; Oxford University Press: New York, NY, USA, 2006. 
88. Crews, F.T.; Boettiger, C.A. Impulsivity, frontal lobes and risk for addiction. Pharmacol. Biochem. Behav. 2009, 93, 237-247. [CrossRef] [PubMed]

89. Giancola, P.R. The underlying role of aggressivity in the relation between executive functioning and alcohol consumption. Addict. Behav. 2007, 32, 765-783. [CrossRef] [PubMed]

90. Rossow, I.; Bogstrand, S.T.; Ekeberg, Ø.; Normann, P.T. Associations between heavy episodic drinking and alcohol related injuries: A case control study. BMC Public Health 2013, 13, 1076. [CrossRef] [PubMed]

91. Young, T.; Peppard, P.E.; Gottlieb, D.J. Epidemiology of obstructive sleep apnea. Am. J. Respir. Crit. Care Med. 2002, 165, 1217-1239. [CrossRef] [PubMed]

92. Scanlan, M.F.; Roebuck, T.; Little, P.J.; Redman, J.R.; Naughton, M.T. Effect of moderate alcohol upon obstructive sleep apnoea. Eur. Respir. J. 2000, 16, 909-913. [CrossRef] [PubMed]

93. Directorate-General for Communication (DG COMM), European Commission. Special Eurobarometer 331, EU Citizens' Attitudes towards Alcohol 2010. Available online: https:/ / ec.europa.eu/health/sites/health/ files/alcohol/docs/ebs_331_en.pdf (accessed on 11 April 2018).

94. Istituto Nazionale di Statistica (ISTAT). Alcohol Consumption in Italy, Year 2016. 2017. Available online: https:/ /www.istat.it/en/files/2017/04/EN_Alcohol_use_abuse2016.pdf?title=Use+of+alcohol+-+12+ Apr+2017+-+Full+text.pdf (accessed on 11 April 2018).

95. Substance Abuse and Mental Health Services Administration (SAMHSA). National Survey on Drug Use and Health 2015. 2016. Available online: https:/ /www.samhsa.gov/data/sites/default/files/NSDUH-DetTabs2015/NSDUH-DetTabs-2015/NSDUH-DetTabs-2015.pdf (accessed on 11 April 2018).

96. World Health Organization (WHO). Global Strategy to Reduce the Harmful Use of Alcohol 2010. Available online: http:/ / www.who.int/substance_abuse/msbalcstragegy.pdf (accessed on 11 April 2018).

97. World Health Organization (WHO), Regional Office for Europe. European Action Plan to Reduce the Harmful Use of Alcohol 2012-2020. 2012. Available online: http://www.euro.who.int/_data/assets/pdf_ file/0008/178163/E96726.pdf (accessed on 11 April 2018).

98. Ministero della Salute. Piano Nazionale della Prevenzione 2014-2018. 2014. Available online: http:/ / www. euro.who.int/_data/assets/pdf_file/0008/178163/E96726.pdf (accessed on 11 April 2018).

99. Vakulin, A.; Baulk, S.D.; Catcheside, P.G.; Anderson, R.; van den Heuvel, C.J.; Banks, S.; McEvoy, R.D. Effects of moderate sleep deprivation and low-dose alcohol on driving simulator performance and perception in young men. Sleep 2007, 30, 1327-1333. [CrossRef] [PubMed]

100. Garbarino, S.; Nobili, L.; Philip, P.; Plazzi, G.; Campus, C.; Morrone, E.; De Carli, F.; SALT Group. Circadian sleep propensity and alcohol interaction at the wheel. J. Clin. Sleep Med. 2016, 12, 1011-1017. [CrossRef] [PubMed]

(C) 2018 by the authors. Licensee MDPI, Basel, Switzerland. This article is an open access article distributed under the terms and conditions of the Creative Commons Attribution (CC BY) license (http://creativecommons.org/licenses/by/4.0/). 